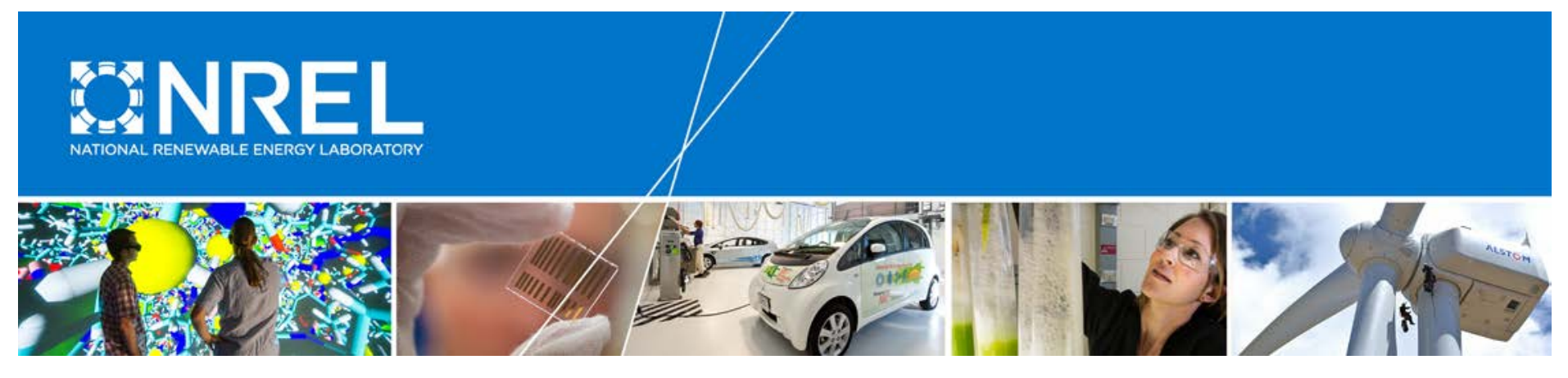

\title{
Energy Efficiency Under Alternative Carbon Policies: Incentives, Measurement, and Interregional Effects
}

Daniel C. Steinberg

National Renewable Energy Laboratory

Erin Boyd

U.S. Department of Energy Office of Energy Policy and Systems Analysis

NREL is a national laboratory of the U.S. Department of Energy Office of Energy Efficiency \& Renewable Energy Operated by the Alliance for Sustainable Energy, LLC

This report is available at no cost from the National Renewable Energy Laboratory (NREL) at www.nrel.gov/publications.

Technical Report

NREL/TP-6A20-64390

August 2015

Contract No. DE-AC36-08GO28308 


\section{Energy Efficiency Under Alternative Carbon Policies: Incentives, Measurement, and Interregional Effects}

Daniel C. Steinberg

National Renewable Energy Laboratory

Erin Boyd

U.S. Department of Energy Office of Energy Policy and Systems Analysis

Prepared under Task No. EPSA.2020

NREL is a national laboratory of the U.S. Department of Energy Office of Energy Efficiency \& Renewable Energy Operated by the Alliance for Sustainable Energy, LLC

This report is available at no cost from the National Renewable Energy Laboratory (NREL) at www.nrel.gov/publications.

National Renewable Energy Laboratory 15013 Denver West Parkway Golden, CO 80401

303-275-3000 • www.nrel.gov

\section{Technical Report}

NREL/TP-6A20-64390

Sugust 2015

Contract No. DE-AC36-08GO28308 


\title{
NOTICE
}

This report was prepared as an account of work sponsored by an agency of the United States government. Neither the United States government nor any agency thereof, nor any of their employees, makes any warranty, express or implied, or assumes any legal liability or responsibility for the accuracy, completeness, or usefulness of any information, apparatus, product, or process disclosed, or represents that its use would not infringe privately owned rights. Reference herein to any specific commercial product, process, or service by trade name, trademark, manufacturer, or otherwise does not necessarily constitute or imply its endorsement, recommendation, or favoring by the United States government or any agency thereof. The views and opinions of authors expressed herein do not necessarily state or reflect those of the United States government or any agency thereof.

This report is available at no cost from the National Renewable Energy Laboratory (NREL) at www.nrel.gov/publications.

Available electronically at SciTech Connect http:/www.osti.gov/scitech

Available for a processing fee to U.S. Department of Energy and its contractors, in paper, from:

\author{
U.S. Department of Energy \\ Office of Scientific and Technical Information \\ P.O. Box 62 \\ Oak Ridge, TN 37831-0062 \\ OSTI http://www.osti.gov \\ Phone: 865.576.8401 \\ Fax: 865.576.5728 \\ Email: reports@osti.gov
}

Available for sale to the public, in paper, from:

\author{
U.S. Department of Commerce \\ National Technical Information Service \\ 5301 Shawnee Road \\ Alexandria, VA 22312 \\ NTIS http://www.ntis.gov \\ Phone: 800.553 .6847 or 703.605 .6000 \\ Fax: 703.605.6900 \\ Email: orders@ntis.gov
}




\section{Acknowledgments}

This work was supported by the U.S. Department of Energy (DOE) Office of Energy Policy and Systems Analysis (EPSA) under Contract No. DE-AC36-08GO28308 with the National Renewable Energy Laboratory. The authors would like to thank Steve Schiller and Annika Todd, Lawrence Berkeley National Laboratory (LBNL), for project advisement; Carla Frisch and John Larsen (EPSA) for key contributions; and John Agan (EPSA), Steve Capanna (DOE Office of Energy Efficiency and Renewable Energy), Jeff Logan and Laura Vimmerstedt (National Renewable Energy Laboratory), Christopher James (Regulatory Assistance Project), Jonas Monast (Nicholas School of the Environment, Duke University), Tomas Carbonell (Environmental Defense Fund), Daniel Kaffine (University of Colorado - Boulder), Karen Palmer (Resources for the Future), and Charles Rossman (Southern Company) for their reviews and insightful comments.

Any remaining errors or omissions in this report are solely the responsibility of the authors. 


\section{Executive Summary}

Rate-based emissions standards (or emissions intensity standards), which impose a limit on the rate (or intensity) of carbon dioxide $\left(\mathrm{CO}_{2}\right)$ emissions from power plants (e.g., tons $\mathrm{CO}_{2}$ per $\mathrm{MWh}$ ), have emerged as a policy type of interest for reducing greenhouse gas (GHG) emission from the power sector. Rate-based standards require that the rate of emissions from covered power plants is less than or equal to a pre-determined intensity target. One important effect of rate-based standards is that, in addition to encouraging reductions in GHG emissions by creating an implicit tax on carbon emissions, they also create an incentive for generation output. This implicit incentive for generation, often referred to as an "output subsidy," has two important consequences. First, if the standard only applies to sources of generation and does not credit energy savings from efficiency ${ }^{1}$ measures, the output subsidy is only received by generation facilities. As a result, the standard creates a disproportionate incentive for investment in generation-based options for emissions reductions, such as fuel switching or increased renewable generation, relative to the incentive for end-use energy efficiency options. Second, the output subsidy lowers the marginal cost of generation, which can lead to reduced electricity prices relative to an optimally designed mass-based policy or equivalent carbon tax, ultimately reducing the value of energy efficiency measures to end-users. Given that energy efficiency measures have been widely recognized as a low- to negative-cost option for reducing emissions, as states or other entities consider alternative policy options for reducing GHGs, it is important to understand the potential effects of alternative policies on the incentives for investment in energy efficiency measures, and to identify design options to mitigate any economic inefficiencies in the incentives.

In this report, we examine and compare how tradable mass-based polices and tradable rate-based policies create different incentives for energy efficiency investments. Through a generalized demonstration and set of examples, we show that as a result of the output subsidy they create, traditional rate-based policies, those that do not credit energy savings from efficiency measures, reduce the incentive for investment in energy efficiency measures relative to an optimally designed mass-based policy or equivalent carbon tax. We then show that this reduced incentive can be partially addressed by modifying the rate-based policy such that electricity savings from energy efficiency measures are treated as a source of zero-carbon generation within the framework of the standard, or equivalently, by assigning avoided emissions credit to the electricity savings at the rate of the intensity target. These approaches result in an extension of the output subsidy to efficiency measures and eliminate the distortion between supply-side and demand-side options for GHG emissions reduction. However, these approaches do not address electricity price distortions resulting from the output subsidy that also impact the value of efficiency measures. Next, we assess alternative approaches for crediting energy efficiency savings within the framework of a rate-based policy. Finally, we identify a number of challenges that arise in implementing a rate-based policy with efficiency crediting, including the requirement to develop robust estimates of electricity savings in order to assess compliance, and the requirement to track the regionality of the generation impacts of efficiency measures to account for their interstate effects.

\footnotetext{
${ }^{1}$ Here and for the rest of this document we use the term "efficiency" inclusively of both end-use efficiency measures and end-use conservation.
} 
Key findings are summarized below.

- Mass-based policies, if designed with a full auction of allowances, generally provide economically efficient incentives for energy efficiency. However, these incentives are eroded under mass-based policies that freely allocate all or a portion of allowances to generators or to load-serving entities (LSEs) based on output. Furthermore, in cost of service regions, assuming regulators only allow utilities and LSEs to recover the cost of allowances purchased, incentives for efficiency improvements will be eroded under any approach that freely allocates allowances to generators or LSEs, regardless of how those allowances are distributed. The extent to which these incentives are eroded depends on the portion of allowances that are freely distributed - the lower the portion that is freely allocated the smaller the impact on the incentives for efficiency improvements.

- Rate-based policies without energy efficiency crediting, as a result of the output subsidy created for generation, provide reduced incentives for investment in energy efficiency measures relative to an economically optimal designed mass-based policy.

- The reduced incentive for efficiency measures under rate-based policies can be partially corrected by modifying the policy such that electricity savings from energy efficiency measures are treated as a source of zero-carbon generation within the framework of the policy. This can be accomplished by either including the savings in the denominator of the intensity fraction (effectively treating efficiency as a load-serving technology), or equivalently by assigning avoided emissions credits to savings in the numerator at the target rate. These approaches recover the same relative incentives for supply- and demand-side abatement options as an optimally designed mass-based policy. Alternative options for crediting electricity savings fail to consistently recover the same relative incentives for efficiency as a first-best mass-based policy.

- Relative to a mass-based policy, a rate-based policy that credits electricity savings creates an additional challenge for assessing compliance because it requires developing robust estimates of the quantity of electricity savings resulting from energy efficiency measures. However, estimates of the avoided emissions associated with those savings are not needed to assign credit to electricity savings because avoided emissions can be calculated as the product of electricity savings and the intensity target.

- Under a rate-based policy, interstate effects of efficiency measures on generation can create accounting challenges with respect to which state receives credit for the offset generation and emissions. Failure to properly account for the interstate effects of efficiency measures can lead to perverse incentives for investment in efficiency and erosion of the intended emissions outcomes of the policy. One of the simplest ways to address these issues is to expand the area over which a single policy applies. Additional options for accounting for these issues are presented in the main body of the report. 


\section{Table of Contents}

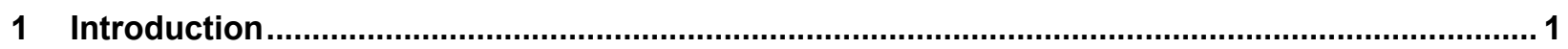

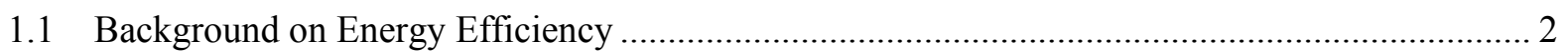

2 Energy Efficiency Under Tradable Mass- and Rate-Based Policies.......................................... 5

2.1 Energy Efficiency Under Mass-Based Polices........................................................................ 5

2.2 Energy Efficiency Under a Tradable Rate-Based Standard without Efficiency Crediting ........... 8

2.3 Energy Efficiency Under a Tradable Rate-Based Standard with Efficiency Crediting............... 12

3 Rate-Based Policy With Efficiency Crediting: Implementation Challenges ................................. 16

3.1 Measuring Electricity and Associated Emissions Savings for Compliance Assessment ............. 16

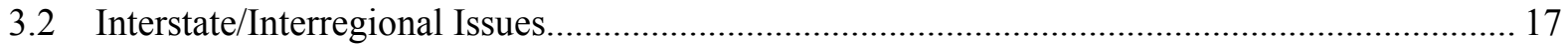

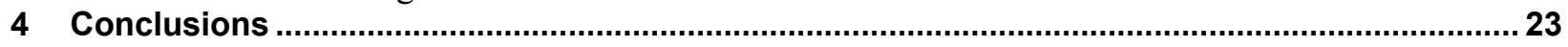

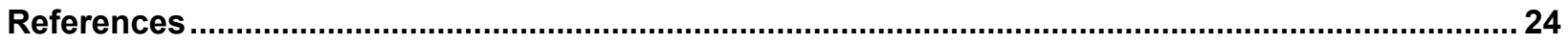

Appendix A. Options to Cost-Effectively Achieve Energy Efficiency Goals .................................. 27

Appendix B. Emissions Crediting of Electricity Savings From Energy Efficiency Under a Rate-

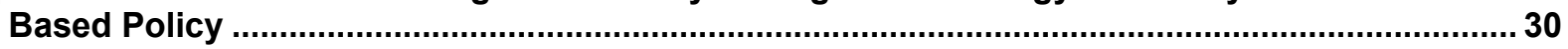

\section{List of Tables}

Table 1. Impact of the Marginal Cost (MC) of Generation of Alternative Technologies and the Marginal Cost of Efficiency Saving Under a Mass-Based Policy with Allowance Auction................... 7

Table 2. Comparison of the Change in the Marginal Cost of Generation of Alternative Technologies and the Marginal Cost of Efficiency Savings Under a Mass-Based Policy with an Allowance Auction and a Rate-Based Policy................................................................................ 11

Table 3. Comparison of the Change in the Marginal Cost of Generation of Alternative Technologies and the Marginal Cost of Efficiency Saving Under Mass-Based with Auction, Rate-Based, and Rate-Based with Efficiency Crediting Policies ................................................................. 15

Table 4. Summary of the Interstate Issues That Arise When Efficiency Measures in One State Lead to Generation and Emissions Effects in Neighboring States................................................ 21

Table B-1. The Generation Mix of the Model Generation System Under No-Policy (Year 1)................. 32

Table B-2. The Equilibrium Generation Mix Under No-Policy and Under the Rate-Based Policy With Efficiency Crediting ................................................................................................... 33

Table B-3. The Static or Non-Equilibrium Effect of Electricity Savings on the Generation Mix Assuming

The Electricity Savings Offset Coal Generation ................................................................ 34

Table B-4. Equilibrium Generation Mix Under No-Policy and Under The Rate-Based Policy With Efficiency Crediting When an Efficiency Measure Offsets Coal Generation......................... 35

Table B-5. Equilibrium Generation Mix Under No-Policy and Under the Rate-Based Policy With Efficiency Crediting When an Efficiency Measure Offsets NGCC Generation ...... 38 


\section{Introduction}

States have leveraged a broad range of policies to reduce greenhouse gas (GHG) emissions from the power sector. These policies have included direct mass-based approaches that create a price for carbon emissions, such as cap-and-trade policies, and indirect approaches that generally result in emissions reductions but do not explicitly require them, such as renewable portfolio standards (RPSs), energy efficiency resource standards (EERSs), appliance standards, and incentives for zero-emissions generation technologies. Direct approaches in the form of massbased cap-and-trade programs have been implemented in California and in the group of states participating in the Regional Greenhouse Gas Initiative (RGGI) ${ }^{2}$ Indirect approaches that are often motivated not only by the emissions reductions associated with these policies but also by their other impacts, such as reducing electricity costs to consumers or stimulating jobs and local economic development, have been implemented in all 50 states. Energy efficiency programs of some form have been implemented in every state (Gilleo et al. 2014), RPSs have been implemented in 29 states, the District of Columbia, and Puerto Rico (Heeter and Bird 2013), and EERSs have been implemented in 23 states (Steinberg and Zinaman 2014). Thus, states have used a diverse set of approaches for reducing GHG emissions.

End-use energy efficiency improvements have long been recognized as low- to negative-cost options for reducing GHG emissions in the power sector (Stobaugh and Yergin 1979; Choi Granade et al. 2009; Arimura et al. 2011; NAS 2010; EPRI 2014). As such, questions have emerged in the context of state policy options for reducing emissions: how do alternative policies incentivize conservation and efficiency investments relative to other options for reducing emissions and how do requirements to measure and track savings from energy efficiency measures differ under these alternative options?

It has been widely shown that optimally designed tradable mass-based policies, namely cap-andtrade programs with full auctions of emissions allowances, can achieve outcomes equivalent to those under a first-best policy of a Pigovian tax (Baumol and Oates 1988). ${ }^{3}$ Under this type of design, the mass-based policy creates a tax on emissions that increases the cost of generation from emitting generators and therefore encourages both substitution towards less emissionsintensive generation and reductions in consumption through efficiency measures.

Recently, tradable rate-based standards for power sector GHG emissions, which set a limit on the average emissions per unit of generation (e.g., tons per MWh) from electricity generators, ${ }^{4}$ have emerged as another policy of interest. One important consequence of rate-based standards is that in addition to providing an incentive to reduce emissions by creating an implicit tax on emissions (similar to mass-based standards), they simultaneously create an implicit subsidy for generation

\footnotetext{
${ }^{2}$ Connecticut, Delaware, Maine, Maryland, Massachusetts, New Hampshire, New York, Rhode Island, and Vermont participate in the RGGI.

${ }^{3}$ A Pigovian tax is a tax applied to an activity that negatively impacts (damages) individuals or firms other than those choosing to carry out the activity. Economic theory demonstrates that this tax, if set at the marginal value of damages, will internalize the damages to those carrying out the activity and therefore lead to an economically efficient level of production.

${ }^{4}$ Rate-based standards do not set a limit on the total quantity of emissions from generators, just the rate of emissions from those generators. Thus, under a rate-based standard, total emissions can be at any level as long as the ratetarget is met.
} 
output (Helfand 1991; Fischer 2001), the "output subsidy," that reduces the incentive for investment in efficiency improvements (Fischer and Newell 2008; Aldy 2012; Paul, Palmer, and Woerman 2014). This reduced incentive for efficiency improvements is manifested by two separate effects. First, under traditional rate-based standards, those that do not credit efficiency, the output subsidy created by the policy is only received by entities producing electricity, that is, by individual generators. Measures that reduce consumption, like efficiency measures, receive nothing and therefore do not benefit from the subsidy. As a result, rate-based standards provide a disproportionate incentive for supply-side abatement measures (e.g., coal to gas fuel switching, increased zero-carbon generation) relative to demand-side abatement options (conservation and efficiency). Second, the output subsidy lowers the cost of generation, which can lead to a reduction in the electricity price, ${ }^{5}$ further decreasing the value of avoided consumption and therefore the incentive for investment in energy efficiency measures. As a result of these two effects, relative to an optimally designed mass-based standard, traditional rate-based standards provide a reduced incentive for efficiency improvements.

In this report, we examine how mass-based and rate-based policies create different incentives for investment in energy efficiency measures. We then demonstrate that by modifying the design of a rate-based policy to allow efficiency measures to contribute towards compliance, the policy eliminates the distortion in incentives between supply- and demand-side abatement options, and recoups the same relative incentives as those achieved under a first-best mass-based program (carbon tax or equivalent cap-and-trade program). Although this modification of the rate-based policy recovers the same relative incentives for alternative abatement options as an optimally designed mass-based policy, it does not recover equivalent absolute incentives, and therefore fails to correct the electricity price distortion associated with the output subsidy. As a result, the modified policy does not recoup first-best outcomes. Finally, we identify a number of challenges that arise in implementing a rate-based standard with efficiency crediting, including the requirement to develop robust estimates of electricity savings in order to assess compliance, and the requirement to track the regionality of the generation impacts of electricity savings in order to account for interstate effects of efficiency measures.

\subsection{Background on Energy Efficiency}

A large body of research and accompanying literature have demonstrated that energy efficiency improvements can potentially drive significant reductions in energy consumption and expenditures and significantly reduce harmful emissions (e.g., particulate matter, $\mathrm{SO}_{2}, \mathrm{NO}_{\mathrm{X}}$, greenhouse gases) associated with energy use at low- to negative-cost ${ }^{6}$ (Choi Granade et al. 2009; NAS 2010; EPRI 2014). As a result, investment in efficiency is often described as a "winwin" solution — at zero- or negative-cost, efficiency improvements save money and lower emissions (Stobaugh and Yergin 1979; Choi Granade et al. 2009).

\footnotetext{
${ }^{5}$ Whether or not changes in the cost of generation lead to changes in electricity price depends on the structure of the electricity market and electricity rate design.

${ }^{6}$ Energy efficiency measures typically involve upfront capital expenditures and result in reductions in future energy use and associated energy expenditures. In many cases, the present discounted value of the future reductions in energy expenditures (i.e. the dollar savings associated with the efficiency measure) may exceed the upfront capital costs. These set of measures are known as negative-cost efficiency measures because the cost-savings exceed the costs.
} 
Although many studies have concluded that this potential to reduce expenditures and emissions associated with electricity consumption exists, a significant portion of this potential has yet to be realized. In short, electricity consumers under-invest in end-use efficiency relative to levels that appear to be cost-effective from an engineering perspective. The difference in the amount of cost-effective efficiency estimated in studies and the amount implemented by consumers to date is typically referred to as the "energy efficiency gap." The existence of this gap has been documented in many case studies and research reports (e.g., Meier et al. 1983). However, there is still an open question as to the size and source of this gap (Allcott and Greenstone 2012); it is likely due to a range of market and behavioral failures that affect consumers' decision-making about investment in end-use energy efficiency (Gillingham, Newell, and Palmer 2009; Gillingham and Palmer 2014).

There are two distinct categories of market failures that may lead to economically inefficient levels of consumption of electricity and investment in efficiency improvements: energy use externalities ${ }^{7}$ and investment inefficiencies ${ }^{8}$ (Allcott and Greenstone 2012). Energy use externalities, such as the damages associated with GHG emissions from fossil-fueled power plants, can be addressed by explicitly or implicitly (e.g., through a tax or cap-and-trade system similar to those already implemented in some states) imposing a tax on the source of the negative externality - in this case, pollution — equal to the marginal social cost of the externality (Pigou 1920). Investment inefficiencies, such as information asymmetries, ${ }^{9}$ capital market failures, ${ }^{10}$ or principal-agent problems, ${ }^{11}$ can in theory be addressed with policies or programs that directly address the market failure. For example, in the case of an information asymmetry, such as consumers undervaluing the expected savings from a high-efficiency refrigerator, the corrective policy would be to provide complete information to the imperfectly informed customers-i.e., accurate estimates of the level of energy and cost-savings associated with the efficient refrigerator.

\footnotetext{
${ }^{7}$ An externality is the cost (negative externality) or benefit (positive externality) associated with production or consumption of a good or service that affects a third party whose preferences are not taken into account when making a decision about the production or consumption of that good or service. For example, the health and environmental costs associated with unregulated pollution from power plants represent a negative externality. ${ }^{8} \mathrm{An}$ investment inefficiency is any type of market failure unrelated to the pricing of the good or service that drives a consumer to either purchase or consume too little or too much of the good or service relative to the economically efficient levels. For example, if financing is required for a purchase, lack of access to financing (with economically efficient interest rates) would impede the purchase of the good.

${ }^{9}$ An information asymmetry occurs when either party in a transaction, producer or consumer, has more or better information than the other party. In the efficiency context, an example of an information asymmetry would be if consumers have inaccurate expectations of the amount of energy and/or cost savings resulting from a particular efficiency measure.

${ }^{10}$ A capital market failure, such as limited or zero-access to capital, is any distortion that alters the cost of financing from the optimal level - effectively, any distortion that causes the effective rate of interest to be too high or too low relative to the efficient level.

${ }^{11}$ A principal-agent problem occurs when one party (the agent) makes decisions on behalf of another party (the principal). This can create economic inefficiencies because the agent may be motivated to act on her own behalf as opposed to the principal's. For example, in the case of rental properties, the owner of a rental property will have little incentive to invest in efficiency measures because the benefits solely accrue to the tenants, assuming the tenant pays the utility bill. Similarly, the tenant may have little incentive to invest in efficiency measures as she will not necessarily recoup their full value - the value will continue to accrue to the next tenant renting the property.
} 
In addition to these two types of market failures, behavioral failures, such as those associated with the prospect theory of decision-making, bounded rationality, and heuristic decision-making, may also lead to inefficient levels of electricity consumption and investment in efficiency (Gillingham, Newell, and Palmer 2009; Allcott and Mullainathan 2010; Gillingham and Palmer 2014). For instance, in efficiency investment, consumers will have a tendency to overweight the upfront costs of a measure relative to the unobservable long term future savings associated with the measure and will therefore have a tendency to under-invest in the measure. ${ }^{12}$

In order for states to fully harness the potential for energy efficiency to reduce emissions, the policies and programs that states implement must address the full suite of market and behavioral failures that affect investment in efficiency measures. A strategy that internalizes the negative externalities of electricity consumption (e.g., emissions budget) but fails to address other market and behavioral failures is unlikely to result in investment in all cost-effective energy efficiency measures. Nevertheless, addressing these externalities is necessary, even if not sufficient. Both theory and empirical evidence have shown that imposing a price on carbon emissions, either through a tax or an equivalent mass-based program, will incentivize investment in the most costeffective strategies for reducing carbon emissions (Baumol and Oates, 1988). While other behavioral failures or other existing market distortions may lead to imperfect investment, the economic incentives created by imposing a price (or tax) on carbon encourage more efficient behavior. However, as discussed briefly above, while rate-based standards provide some incentive for investment in efficiency measures as a means to reduce emissions, if they are not designed appropriately they can over-incentivize supply-side emissions abatement options relative to demand-side options. Therefore, rate-based standards lead to too much investment in supply-side options and too little investment in demand-side options. In this report, we review how mass- and rate-based standards for carbon emissions incentivize energy efficiency investment and show that a simple modification to a rate-based standard can recover the correct relative incentives for demand-side resources.

Although creating efficient incentives for both supply- and demand-side options for emissions abatement is crucial for encouraging cost-effective emissions reductions, additional policies will be necessary to address other market failures and barriers in order to realize all cost-effective efficiency measures, regardless of the type of carbon policy implemented. Appendix A provides an overview of the energy efficiency policies and programs that states could implement in order to overcome the broader suite of market and behavioral failures.

\footnotetext{
${ }^{12}$ Another issue that is sometimes referenced as a source of the energy efficiency gap is the "rebound effect," whereby consumption of energy services increases as a result of energy-efficiency induced declines in the marginal cost of energy services - energy services can be consumed at lower cost following the energy efficiency improvement and thus customers consumer more of them. Although the rebound effect may reduce the energy savings associated with energy efficiency improvements, the rebound effect is not a market or behavioral failure. Rather the rebound effect is the result of consumer response to changes in prices - this will occur even in the absence of any market or behavioral failures.
} 


\section{Energy Efficiency Under Tradable Mass- and Rate- Based Policies}

\subsection{Energy Efficiency Under Mass-Based Polices}

Under a tradable mass-based policy (cap-and-trade), an emissions budget is created that specifies the total amount of $\mathrm{CO}_{2}$ that may be emitted by the regulated entities over a set period of time. The regulator creates a limited number of emissions permits or allowances (in units of mass, e.g., tons) - in total equal to the budget - and either freely distributes or auctions the allowances to the regulated entities (and in some cases to non-regulated entities). ${ }^{13}$ In order to comply, regulated entities are required to surrender an allowance for each ton of $\mathrm{CO}_{2}$ emitted, and are thus faced with the choice to either surrender allowances or reduce their own emissions. Allowances may be traded (bought or sold), which creates a market and a price for carbon emissions allowances. ${ }^{14}$ This carbon price reflects the marginal cost of reducing emissions (at the level of the budget) and acts as an implicit tax on emissions that regulated entities must pay for each unit of $\mathrm{CO}_{2}$ they release. $^{15}$

Under a mass-based policy in which generators are the regulated entities, given that they must pay for each unit of $\mathrm{CO}_{2}$ released, this implicit tax on emissions increases the cost of generation. For every emitting generator, the implicit tax becomes an additional cost for each unit of electricity produced and therefore increases the marginal cost of generation from those units. The magnitude of the increase in the marginal cost depends on the emissions intensity (tons $\mathrm{CO}_{2}$ emitted per MWh produced) of the generator and the stringency of the carbon constraint. Specifically, the implicit tax increases the marginal cost of generation by the product of the allowance price and the emissions intensity of the generator:

Assuming the total cost function for a generator under a mass-based policy is:

$$
\text { Total Cost } \text { Cost }_{i}^{\text {fix }}+\operatorname{Cost}_{i}^{\text {var }} * G_{i}+P_{C} E_{i}
$$

where $\operatorname{Cost}_{i}^{\text {fix }}$ is the fixed costs of the generator, including capital and fixed-operations and maintenance, $\operatorname{Cost}_{i}^{\text {var }}$ is the variable cost including fuel, operations, and maintenance, $G_{i}$ is

\footnotetext{
${ }^{13}$ Whether or not to auction or freely distribute all or a portion of allowances is an important choice in designing a mass-based policy. This choice affects the cost-effectiveness, distributional impacts, and electricity price impacts of the policy. Because allowances have value, regulators can modify the distributional impacts of the policy by adjusting the distribution of the allowances. In some cases the regulator may choose to allocate a portion of the allowances to entities that do not have compliance obligations. The allowances thus act as a source of revenue for these entities. This mechanism has been used to fund efficiency programs (e.g., under California's AB32). This report largely focuses on mass-based policies that auction all allowances, but we also note the effects of freely allocating all or a portion of allowances to generators or load-serving entities.

${ }^{14}$ Allowance markets may only allow trading between regulated entities or may allow non-regulated entities to participate as well.

${ }^{15}$ Typically, the obligation for compliance under a mass-based program is placed on individual sources of emissions, in this case generating units. However, the emission reduction obligation can, alternatively, be placed downstream of generators on LSEs. Placing the obligation on LSEs requires that the carbon intensity of the energy purchased by each LSE is known and tracked. This poses a significant and potentially insurmountable challenge in some regions.
} 
generation from generator $i, E_{i}$ is the emissions from generator $i$, and $P_{C}$ is the price of a carbon allowance. If $I_{i}$ is the carbon intensity of generatori, then substituting in $G_{i} I_{i}$ for $E_{i}$ yields:

$$
\text { Total } \operatorname{Cost}_{i}=\operatorname{Cost}_{i}^{\text {fix }}+\operatorname{Cost}_{i}^{\text {var }} * G_{i}+P_{C} G_{i} I_{i}
$$

Thus the marginal cost of generation from a given generator is:

$$
\frac{\partial\left(\text { Total Cost }_{i}\right)}{\partial\left(G_{i}\right)}=\operatorname{Cost}_{i}^{\text {var }}+P_{C} I_{i}
$$

Under the policy, the marginal cost of generation from emitting generators increases by $P_{C} I_{i}$. This is equivalent to a tax on generation that varies by the carbon intensity of that unit of generation, $I_{i}$. The marginal cost of generation from zero-carbon-emitting generators (with $I_{i}=0$ ), such as nuclear and wind technologies, is unaffected by the policy. Similarly, the marginal cost of energy efficiency measures is unaffected given that they are also effectively zero-emission options for meeting demand.

The policy thus leads to changes in the relative costs of generation among the fleet of generating units (emitting units become more expensive relative to zero-emitting units). This change creates an incentive to substitute away from carbon-intensive generators to low- or zero-carbon generators. This substitution has two key implications for efficiency measures. First, relative to the cost of electricity from emitting generators, energy efficiency measures become cheaper (because the cost of generation from carbon-emitting generators increases). Second, increasing the marginal cost of emitting generators can lead to increases in the electricity price thereby also increasing the value of efficiency measures. ${ }^{16}$ Both of these effects can be impacted by the distribution of emissions allowances. In particular, if allowances are freely distributed based on output rather than auctioned (i.e., if they are allocated to individual generators in proportion to the amount of energy they generate) then the change in the marginal costs of efficiency measures relative to that of generators will be diminished, as will any changes in electricity price resulting from the policy. Furthermore, the electricity price impacts of the policy will also depend on the structure of the electricity market. We explore this issue in greater detail below.

Table 1 shows the impact of a mass-based policy with auctioned allowances on the marginal cost of generation from a set of stylized generators and on an efficiency measure. In the table it is assumed that the price of an allowance, $P_{C}$, is $\frac{\$ 20}{\operatorname{ton} \mathrm{CO}_{2}} \cdot{ }^{17}$ The table illustrates that the marginal cost of generation from any emitting generator, in this case coal and natural gas combined cycle (NGCC) units, increases relative to the marginal cost of efficiency measures.

\footnotetext{
${ }^{16}$ The direct value of an efficiency measure to a consumer is primarily the avoided cost of energy consumption. As a result, electricity prices (and the total amount of electricity consumption avoided) determine the value of efficiency improvements to a consumer.

${ }^{17}$ The nominal price of allowances of $\$ 20 /$ ton used in this example is arbitrarily chosen, but falls within the range of allowance prices observed in existing carbon markets such as California's, RGGI's, and the EU Emissions Trading System, and the estimated social cost of carbon (Interagency Working Group on the Social Cost of Carbon, 2013).
} 
Table 1. Example Demonstrating the Impact of the Marginal Cost (MC) of Generation of Alternative Technologies and the Marginal Cost of Efficiency Saving Under a Mass-Based Policy with Allowance Auction

\begin{tabular}{|c|c|c|c|c|c|}
\hline Tech & $\begin{array}{c}\text { Carbon } \\
\text { Intensity } \\
\text { tons/MWh }\end{array}$ & $\begin{array}{l}\text { Marginal } \\
\text { Cost - No } \\
\text { Policy } \\
\$ / M W h\end{array}$ & $\begin{array}{l}\text { Effective } \\
\text { Tax } \\
\$ / M W h\end{array}$ & $\begin{array}{c}\text { Marginal } \\
\text { Cost - with } \\
\text { Policy } \\
\$ / \mathrm{MWh}\end{array}$ & $\begin{array}{c}\text { Change in } \\
\text { Marginal Cost } \\
\text { (dMC) Relative to } \\
\text { dMC of Efficiency } \\
\$ / M W h \\
\end{array}$ \\
\hline General & $\mathrm{I}_{\mathrm{i}}$ & $M C_{i}$ & $P_{C} * I_{i}$ & $M C_{i}+P_{C} * I_{i}$ & $\mathrm{dMC}_{\mathrm{i}}-\mathrm{dMC}_{\mathrm{EE}}$ \\
\hline Coal & 1 & $\mathrm{MC}_{\text {coal }}$ & 20 & $\mathrm{MC}_{\text {Coal }}+20$ & 20 \\
\hline NGCC & 0.5 & $\mathrm{MC}_{\mathrm{NGCC}}$ & 10 & $\mathrm{MC}_{\mathrm{NGCC}}+10$ & 10 \\
\hline $\begin{array}{r}\text { Non-emitting } \\
\text { (e.g. Nuclear or } \\
\text { Wind) }\end{array}$ & 0 & $\mathrm{MC}_{\text {Non }}$ & - & $\mathrm{MC}_{\text {Non }}$ & 0 \\
\hline Efficiency & 0 & $\mathrm{MC}_{\mathrm{EE}}$ & - & $M C_{E E}$ & 0 \\
\hline
\end{tabular}

Note: Assumes allowance price equal to $\$ 20 /$ ton $\mathrm{CO}_{2}$.

These impacts are expected under any mass-based policy that auctions allowances. A policy that freely allocates allowances to generators based on volumes of output would result in different impacts on the relative costs of generation of alternative technologies as the distribution of those free allowances would act as an output subsidy to generators. ${ }^{18}$ The total effect of the tax and subsidy under an output based allocation would be equivalent to that achieved under a rate-based policy and thus the discussion of the impact of a rate-based policy on relative costs below also applies to a mass-based policy with output-based allocation.

The impact of the policy on the electricity price similarly depends on the allowance allocation, but also on the structure of the electricity market. In regions with competitive electricity markets, the generation component of the electricity price is set by the marginal cost of generation of the marginal generator, which is typically a fossil-fueled generator. As a result, under a mass-based policy the wholesale electricity price will include the cost of the emissions allowances. Thus, to the extent that the retail price reflects the wholesale price, ${ }^{19}$ the carbon price will be passed through to retail prices and consumers.

This effect will hold in competitive regions regardless of whether allowances are auctioned or given away, with the exception of a case in which allowances are freely distributed to generators based on output. This is a result of the fact that use of allowances represents either a true cost or an opportunity cost and therefore will be represented in the marginal cost of generation and bid prices. However, if allowances are freely allocated to generators based on output, the allowances become a subsidy to generation, which lowers the marginal cost of generation relative to costs under an auction or other allocation approach. This cost reduction mitigates the price effects of the policy and lowers the value of efficiency measures.

In regions with cost-of-service pricing, presuming that regulators will only allow recovery of actual costs, payments made for allowances are a true cash outlay and regulators will allow

\footnotetext{
${ }^{18}$ Similarly, in cost-of-service regions, any method of freely allocating some portion of allowances will result in different impacts on the relative costs of generators.

${ }^{19}$ Retail market distortions could affect the extent to which wholesale prices are passed onto consumers.
} 
generators or LSEs to recover those costs through increased electricity prices. However, if allowances are freely allocated to generators or to LSEs for the purposes of rate reduction (or equivalently if allowance auction revenues are recycled to generators or LSEs), regulators will presumably not allow generators to pass the opportunity cost of the freely allocated allowances on to customers because there are no true cash outlays associated with securing these allowances. As a result, the effect of a mass-based program on the electricity price in a region with cost-ofservice pricing will likely be diminished under any allocation approach that freely allocates allowances (or auction revenues) to generators or LSEs. ${ }^{20}$ Therefore, the electricity price will not fully reflect the carbon price, and the value of energy efficiency measures to consumers will be diminished.

\subsection{Energy Efficiency Under a Tradable Rate-Based Standard without Energy Efficiency Crediting}

A rate-based standard, rather than limiting the total mass of carbon emissions (tons $\mathrm{CO}_{2}$ ), places a limit on the allowable rate of carbon emissions (tons $\mathrm{CO}_{2} / \mathrm{MWh}$ ) from individual generators. Generators are permitted to trade carbon credits such that generators that do not meet the standard (generators with emissions rates greater than the target) can purchase credits from those that outperform the standard (generators with emissions rates lower than the target) in order to achieve compliance. With this approach, the target is achieved on average across the entire fleet of generators, although the rate of emissions from individual generators may be above or below the target rate.

Specifically, under a tradable rate-based standard, a generator's achieved emissions rate, $I_{A}$, (based on actual emissions, $E_{i}$, minus credits owned or purchased, $C_{i}$ ), must be less than or equal to the target intensity, $I_{T}$ :

$$
I_{A}=\frac{E_{i}-C_{i}}{G_{i}} \leq I_{T}
$$

Or equivalently:

$$
I_{A}=\frac{E_{i}}{G_{i}}-\frac{C_{i}}{G_{i}}=I_{i}-\frac{C_{i}}{G_{i}} \leq I_{T}
$$

where $I_{i}$ is the actual emissions intensity of generator $i$.

Generators that have a lower emission intensity, $I_{i}$, than the target earn credits that can be sold to other facilities, while generators that have a higher emission intensity than the target must either lower their emission rate through facility improvements or purchase sufficient credits from other generators such that their achieved intensity is at or below the target. The achieved intensity could in theory be above the target if the generator fails to purchase sufficient credits to achieve compliance with the policy or potentially below the target if the generator chooses not to sell

\footnotetext{
${ }^{20}$ For further discussion of the impact of a mass-based policy on electricity prices under alternative allocation approaches and regulatory structures, see Sijm, Chen, and Hobbs (2012), Hahn and Stavins (2010), Kopp and Pizer (2007), and Burtraw, Kahn, and Palmer (2005).
} 
surplus credits. ${ }^{21}$ Note, however, that if all generators are in compliance and equilibrium is achieved, then $I_{A}=I_{T}$. We assume equilibrium conditions in the discussion below.

Substituting in $G_{i} I_{i}$ for $E_{i}$ and rearranging equation (4), we see that the number of credits, $C_{i}$, that each generator owes (or earns) depends on the level of generation from the generator and its intensity relative to the target. Specifically, each generator owes (earns) a credit for each ton of $\mathrm{CO}_{2}$ per MWh of generation that its emission rate is above (below) the standard:

$$
C_{i}=G_{i}\left(I_{i}-I_{T}\right)
$$

where $C_{i}$ is the number of net credits owed (if positive) or earned (if negative) by each generating unit.

Similar to a mass-based policy, the trade of credits between generators creates a market and a price for carbon credits under a rate-based policy. However, rearranging equation (6) highlights the key difference between the two policies:

$$
C_{i}=G_{i} I_{i}-G_{i} I_{T}
$$

Under a rate-based policy, each generator is effectively given credits for each unit of generation at the rate of the target intensity $\left(G_{i} I_{T}\right.$ in equation 7$)$ and is required to hold (owes) credits at the rate of its own intensity $\left(G_{i} I_{i}\right.$ in equation 7$)$. The total cost (value) of the credits owed (earned) by the generator is equal to the product of the credit price and the number of credits owed (earned):

$$
\begin{aligned}
& \text { Total Cost }(\text { Value }) \text { of Credits }=P_{C} C_{i}=P_{C}\left(G_{i} I_{i}-G_{i} I_{T}\right) \\
& =P_{C} * E_{i}-P_{C} I_{T} G_{i}
\end{aligned}
$$

where $P_{C}$ is the price of a credit, and emissions, $E_{i}$, is substituted for $G_{i} I_{i}$.

The total cost of generation is thus:

$$
\text { Total Cost }_{i}=\operatorname{Cost}_{i}^{\text {fix }}+\operatorname{Cost}_{i}^{\text {var }} G_{i}+P_{C} G_{i} I_{i}-P_{C} I_{T} G_{i}
$$

And the marginal cost of generation is:

$$
\frac{\partial\left(\text { Total } \operatorname{Cost}_{i}\right)}{\partial\left(G_{i}\right)}=\operatorname{Cost}_{i}^{\text {var }}+P_{C} I_{i}-P_{C} I_{T}
$$

Assuming the policy is binding ${ }^{22}$ and the credit price, $P_{C}$, is non-zero, the rate-based policy creates an implicit tax on emissions ( $P_{C}$ in the first term of equation 9 ) equivalent to that created

\footnotetext{
${ }^{21}$ If a rate-based policy has multiple compliance periods and allows banking of credits, a facility owner may choose to bank credits.

${ }^{22}$ Note that we use the term "binding" to indicate that the policy has an impact on outcomes within the electric sector or, alternatively, that the policy constrains how the electric sector operates. A non-binding policy has no impact on the sector and therefore would result in no changes. "Binding" in this context does not describe a legal
} 
under the mass-based policy, ${ }^{23}$ but also creates an implicit subsidy for generation, the output subsidy, equal to the product of the credit price and the target intensity $\left(P_{C} I_{T}\right.$ in equation 9). ${ }^{24}$ As a result, the net effect of the policy on the marginal cost of generation depends on the aggregate effect of both the tax and the subsidy, $P_{C} I_{i}-P_{C} I_{T}$. Generators with intensities above the target $\left(I_{i}>I_{T}\right)$ will receive a net tax, while generators with intensities below the target $\left(I_{i}<I_{T}\right)$ will receive a net subsidy. This has two important implications for energy efficiency. First, because only generators are covered under the policy, energy efficiency measures do not receive the output subsidy. As a result, relative to a mass-based policy with auctioned allowances, efficiency measures are placed at a disadvantage relative to generators. Generators with intensities greater than the target are taxed, but at a lower rate compared to a mass-based policy with auction, and leading them to be lower cost relative to energy efficiency measures under the traditional ratepolicy. Generators with intensities less than the target are subsidized (as opposed to receiving a small or zero-tax under a mass-based) and therefore are also cheaper relative to efficiency measures. As a result, traditional rate-based standards create a disproportionate incentive to invest in supply-side options for abatement over demand-side options. Second, because the output subsidy mitigates the impact on the marginal cost of generation, electricity price impacts are also mitigated and therefore reduce the value of efficiency measures to consumers.

Table 2 compares the marginal cost impacts of a mass-based policy with a full auction and a rate-based policy. The rate-based policy assumes an intensity target, $I_{T}$, of 0.4 tons $/ M W h$. We assume a carbon price of $\$ 20 /$ ton $\mathrm{CO}_{2}$ under both the mass- and rate-based policies. ${ }^{25}$

obligation; a policy may be legally binding but not stringent enough to impose any additional compliance cost on the obligated entity.

${ }^{23}$ This assumes an equivalent carbon price under the two policies.

${ }^{24}$ The tax and subsidy components of the rate-based policy can be further seen by rearranging the units of eq. 9: $\frac{\$}{\text { ton }} *$ tons $-\frac{\$}{\text { ton }} * \frac{\text { tons }}{M W h} * M W h=\frac{\$}{\text { ton }} * \boldsymbol{t o n s}-\frac{\$}{\boldsymbol{M W h}} * \boldsymbol{M W h} ;$ the first term $\left[\frac{\$}{\text { ton }} *\right.$ tons $]$ is a tax on emissions and the second term $\left[\frac{\$}{M W h} * M W h\right]$ is a subsidy to generation.

${ }^{25}$ Under inelastic demand for electricity, a mass- and rate-based standard with equivalent carbon prices will yield equivalent emissions levels. This is due to the fact that if the carbon price is equivalent between the policies, the dispatch order of technologies is also equivalent, despite the marginal costs being reduced under the rate-based policy. Given equivalent carbon prices, the implicit tax for each generator under the mass-based policy is equivalent to the implicit tax for each generator under the rate-based policy. The difference is that the rate-based policy also includes the output subsidy. However, the output subsidy is constant across generators and therefore shifts the supply curve for generation downward, but maintains the dispatch order. 
Table 2. Illustrative Example Comparing the Change in the Marginal Cost of Generation of Alternative Technologies and the Marginal Cost of Efficiency Savings Under a Mass-Based Policy with an Allowance Auction and a Rate-Based Policy

\begin{tabular}{|c|c|c|c|c|c|c|c|c|c|}
\hline \multirow[b]{2}{*}{ Tech } & & \multicolumn{4}{|c|}{ Mass-Based w/ Auction } & \multicolumn{4}{|c|}{ Rate-Based } \\
\hline & $\begin{array}{l}\text { Carbon } \\
\text { Intensity } \\
\text { tons/MWh }\end{array}$ & $\begin{array}{c}\text { Tax } \\
\$ / M W h\end{array}$ & $\begin{array}{l}\text { Subsidy } \\
\$ / M W h\end{array}$ & $\begin{array}{l}\text { Total Effect } \\
\$ / M W h\end{array}$ & $\begin{array}{c}\text { Change in } \\
\text { Marginal } \\
\text { Cost (dMC) } \\
\text { Relative to } \\
\text { dMC- } \\
\text { Efficiency } \\
\$ / M W h\end{array}$ & $\begin{array}{c}\text { Tax } \\
\$ / M W h\end{array}$ & $\begin{array}{l}\text { Subsidy } \\
\$ / M W h\end{array}$ & $\begin{array}{l}\text { Total } \\
\text { Effect } \\
\$ / M W h\end{array}$ & $\begin{array}{c}\text { Change in } \\
\text { Marginal } \\
\text { Cost (dMC) } \\
\text { Relative to } \\
\text { dMC- } \\
\text { Efficiency } \\
\$ / M W h\end{array}$ \\
\hline General & $I_{i}$ & $P_{c} * I_{i}$ & - & $P_{C} * I_{i}$ & $\mathrm{dMC}_{\mathrm{i}}-\mathrm{dMC}_{\mathrm{EE}}$ & $P_{C} * I_{i}$ & $-P_{C} * I_{T}$ & $P_{C} * I_{i}-P_{C} * I_{T}$ & $d M C_{i}-d M C_{E E}$ \\
\hline Coal & 1 & 20 & - & 20 & 20 & 20 & -8 & 12 & 12 \\
\hline NGCC & 0.5 & 10 & - & 10 & 10 & 10 & -8 & 2 & 2 \\
\hline $\begin{array}{l}\text { Wind or } \\
\text { Nuclear }\end{array}$ & 0 & - & - & 0 & 0 & 0 & -8 & -8 & -8 \\
\hline Efficiency & 0 & - & - & 0 & 0 & - & - & - & - \\
\hline
\end{tabular}

Notes: Assumes equivalent allowance and credit prices, $\boldsymbol{P}_{\boldsymbol{C}}$, equal to a nominal $\$ 20 /$ ton $\mathrm{CO}_{2}$ and a target, $\boldsymbol{I}_{T}$, of 0.4 tons $\mathrm{CO}_{2} / \mathrm{MWh}$.

In the example shown in Table 2, the marginal cost of a coal generator increases by $\$ 20 / \mathrm{MWh}$ under the mass-based policy, but by only $\$ 12 / \mathrm{MWh}$ under the rate-based policy due to the implicit output subsidy of $\$ 8 / \mathrm{MWh}$. Yet, relative to other supply-side technologies, the change in the marginal costs of generation from a coal unit is equivalent under both policies. Under both the mass- and the rate-based policy, the marginal cost of generation from coal increases by $\$ 20 / \mathrm{MWh}$ relative to wind or nuclear and by $\$ 10 / \mathrm{MWh}$ relative to natural gas. However, relative to energy efficiency, the change in the marginal costs of generation from different technologies as a result of the policies is different. Under the mass-based policy, the marginal cost of coal increases by $\$ 20 / \mathrm{MWh}$ relative to efficiency, whereas under the rate-based policy, it increases by $\$ 12 / \mathrm{MWh}$. Thus, relative to the marginal cost of an energy efficiency measure, the marginal cost of coal generation increases under both policies, but by a lesser amount under the rate-based policy. As a result, coal and other emitting generators have a relative advantage under rate-based polices when compared to a mass-based policy with a full allowance auction.

Furthermore, zero emissions generation technologies are also advantaged relative to efficiency measures under the rate-based policy. Under the mass-based policy, wind, nuclear, and energy efficiency are all unaffected, while emitting generators are taxed. Under the rate-based policy, non-emitting generators (e.g. wind and nuclear) receive a subsidy, while energy efficiency measures receive nothing. Thus, non-emitting generators are advantaged relative to energy efficiency measures under a rate-based policy. 
As a result, the rate-based policy generally disadvantages efficiency measures relative to supplyside measures for emissions reductions due to the fact that (1) the policy creates an output subsidy for generation technologies that is not received by efficiency measures and (2) as a result of this subsidy, electricity price impacts are mitigated relative to a mass-based policy with an allowance auction, thereby decreasing the value of end-use efficiency measures. ${ }^{26}$

\subsection{Energy Efficiency Under a Tradable Rate-Based Standard with Efficiency Crediting}

Given that a rate-based standard provides a reduced incentive for efficiency measures, potential modifications to the policy that mitigate or eliminate the distortion between supply-side and demand-side options for reducing emissions may be desirable. One approach is to effectively give avoided emissions credit to energy savings resulting from energy efficiency measures. This can be achieved by including energy savings resulting from energy efficiency measures within the denominator of the intensity fraction. We refer to this modified intensity fraction as the adjusted intensity:

$$
\frac{E_{i}-C_{i}}{G_{i}+G_{i}^{E E}}=I_{A} \leq I_{T}
$$

where $G_{i}^{E E}$ is the total electricity savings resulting from an investment by generator $i$ in an enduse efficiency improvement, $G_{i}$ is generation by generator $i$, and $I_{A}$ is the adjusted achieved (or measured) intensity. ${ }^{27}$ For this section, we will refer to the achieved adjusted intensity with the shorthand of "adjusted intensity." This approach effectively treats energy savings from efficiency measures as an additional source of zero-emitting generation-efficiency is serving load by reducing the amount of energy required to deliver an energy service - and allows reductions in consumption through efficiency measures to contribute towards compliance with the policy. Counting energy savings in the denominator of the intensity fraction results in an extension of the output subsidy to efficiency measures, except now "output" is measured as the sum of energy generated and energy saved. Extending the output subsidy to energy savings corrects the distortion in the relative incentives for generation and efficiency measures such that the cost of efficiency measures relative to other technologies is equivalent to those achieved under an optimal mass-based policy.

Table 3 reproduces Table 2, but adds an examination of a rate-based policy with efficiency crediting. Comparing the bolded columns shows that this approach to crediting energy savings from efficiency measures within a rate-based policy results in the same relative incentives for

\footnotetext{
${ }^{26}$ The stylized example shown in Table 2 assumes equivalent credit prices under the mass- and rate-based standards. Under inelastic demand for electricity, a mass- and rate-based standard with equivalent credit prices will yield equivalent emissions levels. However, under elastic demand the credit price will need to rise under a rate-based policy in order to achieve equivalent emissions to an optimal mass-based policy. This increase in the credit price will result in an increase in the electricity price, however, the equilibrium electricity price under the rate-based policy will remain below that under an optimal mass-policy. Thus, under elastic demand the electricity price distortion will lower the value of efficiency measurements, but not to the same degree as under inelastic demand conditions. The net effect of the rate-based standard on the incentive for investment in efficiency will therefore depend on the electricity price under the policy and the magnitude of the output subsidy.

${ }^{27}$ Note that $I_{A}=I_{T}$ if the generator or state (depending on the obligated entity) is in compliance with the standard.
} 
efficiency and supply-side options as are achieved under a mass-based policy with auctioned allowances. Furthermore, under the rate-based policy with efficiency crediting, the change in the marginal cost of efficiency measures relative to other technologies is equivalent to the change in the marginal cost of zero-carbon generation sources. In other words, the incentive that the policy creates for efficiency measures is equivalent to that created for other zero-carbon technologies.

Although crediting efficiency savings recovers the same relative incentives for efficiency and supply-side options for abatement (and therefore removes the distortion between incentives for generation and efficiency measures), because the output subsidy still exists, crediting efficiency does not recoup equivalent absolute incentives to an optimal mass-based policy. As a result, the rate-based policy with crediting does not correct the distortion in electricity prices. Rather than removing the subsidy for generation (which would eliminate this distortion), crediting efficiency extends the subsidy to efficiency measures, thereby subsidizing all options for meeting load both generation and efficiency. This subsidy for generation and energy savings thus reduces the cost of meeting load and creates a distortion in the price of electricity. Under a rate-based standard with efficiency crediting the value of an efficiency measure is determined by the value of avoided consumption (the electricity price) and the value of the subsidy (the credit price).

Thus, this distortion in the electricity price will affect the value of energy efficiency investments. Fell, Kaffine, and Steinberg (forthcoming) show that this has important consequences under conditions of elastic demand. 


\section{Alternative Approaches for Crediting Savings from Efficiency Measures}

An alternative but equivalent approach that provides the correct incentives for energy efficiency as treating energy savings as a source of generation in the denominator of the intensity fraction is to assign avoided emissions credits to energy savings and subtract those emissions credits from the numerator.

Rearranging equation (12) demonstrates that denominator crediting is equivalent to reducing the emissions in the numerator by the product of electricity savings and the adjusted intensity $\left(I_{A}\right.$, as calculated in equation 12):

$$
\frac{E_{i}-C_{i}-I_{A} G_{i}^{E E}}{G_{i}} \leq I_{T}
$$

As noted earlier, if all generators are in compliance with the policy (that is, if equilibrium is achieved), then $I_{A}=I_{T}$. In that case, equation 13 becomes:

$$
\frac{E_{i}-C_{i}-I_{T} G_{i}^{E E}}{G_{i}} \leq I_{T}
$$

Thus, under equilibrium, treating electricity savings as a source of generation is equivalent to assigning the electricity savings avoided emissions credits at the rate of the target intensity, $I_{T}$. Although mathematically equivalent, conceptually, the numerator crediting approach explicitly calculates the avoided emissions associated with the efficiency measure (as the product of the target and the efficiency savings) while the denominator approach treats efficiency measures as a source of generation and implicitly accounts for the emissions effects.

Appendix B provides a detailed derivation of the equivalence between the denominator and numerator crediting approaches. In addition, Appendix B evaluates other efficiency crediting approaches that have been proposed in the context of a rate-based policy, namely crediting savings at the carbon intensity of offset generation and crediting savings at the carbon intensity of the power pool. We show that under inelastic demand conditions these two approaches assign either too few or too many avoided emissions credits to electricity savings and, as a result, can lead to inefficient incentives for energy efficiency measures and erosion of the intended emissions outcomes of the policy. Specifically, we show that assigning credit to electricity savings based on the carbon intensity of offset generation implicitly ignores the total effects of the electricity savings over the entire year (or compliance period) and therefore results in over- or under-crediting of electricity savings with avoided emissions. Assigning credit to electricity savings based on the average carbon intensity of the power pool implicitly assumes that the boundaries of the rate-based policy correspond to the boundaries of the state. Given that power pools do not typically follow state lines, this will similarly lead to over- or under-crediting of electricity savings with avoided emissions. Thus, the only approaches that reflect the integrated effect of efficiency measures on emissions and recover equivalent relative incentives for energy efficiency and supply side options as those achieved under an optimal mass-based policy are the approaches that treat savings as a source of generation in the denominator or credit efficiency with emissions savings in the numerator at the target rate. 
Table 3. Illustrative Example Comparing the Change in the Marginal Cost of Generation of Alternative Technologies and the Marginal Cost of Efficiency Saving Under Mass-Based with Auction, Rate-Based, and Rate-Based with Efficiency Crediting Policies

\begin{tabular}{|c|c|c|c|c|c|c|c|c|c|c|c|c|c|}
\hline \multirow[b]{2}{*}{ Tech } & & \multicolumn{4}{|c|}{ Mass-Based w/ Auction } & \multicolumn{4}{|c|}{ Rate-Based } & \multicolumn{4}{|c|}{ Rate-Based with Efficiency Crediting } \\
\hline & $\begin{array}{c}\text { Carbon } \\
\text { Intensity } \\
\text { tons/MWh }\end{array}$ & $\begin{array}{c}\text { Tax } \\
\$ / M W h \\
\end{array}$ & $\begin{array}{l}\text { Subsidy } \\
\$ / M W h\end{array}$ & $\begin{array}{l}\text { Total } \\
\text { Effect } \\
\$ / M W h\end{array}$ & $\begin{array}{c}\text { Change in } \\
\text { Marginal } \\
\text { Cost (dMC) } \\
\text { Relative to } \\
\text { dMC- } \\
\text { Efficiency } \\
\$ / M W h \\
\end{array}$ & $\begin{array}{c}\operatorname{Tax} \\
\$ / M W h \\
\end{array}$ & $\begin{array}{l}\text { Subsidy } \\
\$ / M W h\end{array}$ & $\begin{array}{l}\text { Total } \\
\text { Effect } \\
\$ / M W h\end{array}$ & $\begin{array}{l}\text { Change in } \\
\text { Marginal Cost } \\
\text { (dMC) Relative } \\
\text { to dMC- } \\
\text { Efficiency } \\
\$ / M W h \\
\end{array}$ & $\begin{array}{c}\text { Tax } \\
\$ / M W h\end{array}$ & $\begin{array}{l}\text { Subsidy } \\
\$ / M W h\end{array}$ & $\begin{array}{c}\text { Total } \\
\text { Effect } \\
\$ / M W h \\
\end{array}$ & $\begin{array}{l}\text { Change in } \\
\text { Marginal Cost } \\
\text { (dMC) } \\
\text { Relative to } \\
\text { dMC- } \\
\text { Efficiency } \\
\$ / M W h \\
\end{array}$ \\
\hline General & $I_{i}$ & $P_{c} * I_{i}$ & - & $\mathrm{P}_{\mathrm{C}} * \mathrm{I}_{\mathrm{i}}$ & $d M C_{i}-d M C_{E E}$ & $\mathrm{P}_{\mathrm{C}} * \mathrm{I}_{\mathrm{i}}$ & $-P_{C} * I_{T}$ & $\mathrm{P}_{\mathrm{C}} * \mathrm{I}_{\mathrm{i}}-\mathrm{P}_{\mathrm{C}} * \mathrm{I}_{\mathrm{T}}$ & $d M C_{i}-d M C_{E E}$ & $P_{c} * I_{i}$ & $-P_{C} * I_{T}$ & $\mathrm{P}_{\mathrm{C}} * \mathrm{I}_{\mathrm{i}}-\mathrm{P}_{\mathrm{C}} * \mathrm{I}_{\mathrm{T}}$ & $d M C_{i}-d M C_{E E}$ \\
\hline Coal & 1 & 20 & - & 20 & 20 & 20 & -8 & 12 & 12 & 20 & -8 & 12 & 20 \\
\hline NGCC & 0.5 & 10 & - & 10 & 10 & 10 & -8 & 2 & 2 & 10 & -8 & 2 & 10 \\
\hline $\begin{array}{l}\text { Wind or } \\
\text { Nuclear }\end{array}$ & 0 & - & - & 0 & 0 & 0 & -8 & -8 & -8 & 0 & -8 & -8 & 0 \\
\hline Efficiency & 0 & - & - & 0 & 0 & - & - & - & - & 0 & -8 & -8 & 0 \\
\hline
\end{tabular}

Notes: Assumes equivalent allowance and credit prices, $\boldsymbol{P}_{\boldsymbol{C}}$, equal to $\$ 20 /$ ton $\mathrm{CO}_{2}$ and a target, $\boldsymbol{I}_{\boldsymbol{T}}$, of 0.4 tons $\mathrm{CO}_{2} / \mathrm{MWh}$. 


\section{Rate-Based Policy With Efficiency Crediting: Implementation Challenges}

\subsection{Measuring Electricity and Associated Emissions Savings for Compliance Assessment}

Given that a mass-based policy limits the total amount of emissions, assessment of compliance is relatively straightforward. If the sum of the emissions from covered generating units is equal to or less than the specified budget, the state is in compliance. Although there may be a benefit to understanding the relative contributions of individual measures or programs towards meeting the budget (e.g., in order to evaluate the impact or cost-effectiveness of individual measures or programs), there is no need to make this determination for the sake of compliance assessment. The only metric of consequence for compliance assessment is whether or not the emissions budget is met. Individual generators already monitor and report carbon dioxide emissions as a requirement under the Environmental Protection Agency's Greenhouse Gas Reporting Program, ${ }^{28}$ so compliance assessment under a mass-based policy does not create any additional burden for states.

A rate-based policy limits the rate of emissions from generators. In other words, a rate-based policy limits the ratio of emissions to covered or qualified "sources" of generation. Assessing compliance with a rate-based policy thus requires measuring both emissions and qualified sources of generation. In the case of a rate-based policy with efficiency crediting, the qualified sources include electricity savings resulting from end-use efficiency measures. Because savings from energy efficiency cannot be directly measured, a rate-based policy with efficiency crediting creates the additional challenge of developing estimates of the amount of electricity savings resulting from efficiency measures. Furthermore, it is crucial that the estimates of savings are rigorous, as over-estimates or exaggerated estimates could result in erosion of the intended policy effects. Similarly, it is important that states only credit savings that are additional to those included in the energy demand baseline, otherwise the intended emissions outcome of the policy may be eroded..

Regardless of the policy instrument being considered, if efficiency measures are being used to reduce GHG emissions there will be a desire to estimate the amount of electricity savings being achieved by those measures, what the emissions implications of the measures are, and ultimately how cost-effectively the measures are reducing emissions. However, a crucial difference exists between a mass-based policy and a rate-based policy with efficiency crediting: under a massbased policy, compliance can be assessed solely through the measurement of emissions; under a rate-based policy with efficiency crediting, compliance assessment requires measurement of emissions and generation as well as electricity savings. Inaccurate measurement of these savings or including savings from measures that are not additional to the baseline could lead to unintended emissions outcomes - emissions reductions associated with the policy could be greater than or less than intended.

\footnotetext{
${ }^{28}$ EPA Greenhouse Gas Reporting Program, http://www.epa.gov/ghgreporting/.
} 
It is also important to note that although accurate estimates of electricity savings are crucial under a rate-based policy with efficiency crediting, neither estimates of the emissions savings resulting from those electricity savings nor the type of generation offset by the electricity savings is needed for the assessment. Recall from equation 12 that under equilibrium conditions, including electricity savings as a term in the denominator of the adjusted intensity fraction (equation 15) is equivalent to reducing the emissions in the numerator by the product of electricity savings and the target intensity (equation 16):

$$
\begin{aligned}
& I_{T} \geq \frac{\sum \text { Emissions }}{\sum \text { Generation }+\sum \text { Electricity Savings }} \\
& I_{T} \geq \frac{\sum \text { Emissions }-I_{T} * \text { EElectricity Savings }}{\sum \text { Generation }}
\end{aligned}
$$

Although equation 14 implies an adjustment of the emissions quantity in the numerator, this adjustment can be calculated solely as the product of the estimated electricity savings and the target intensity $\left(I_{T}\right)$. There is no need to determine the type of generation technology or the amount of emissions that was offset at the time the efficiency measure was reducing electricity consumption. The only emissions data required are total emissions from EGUs. In fact, assigning carbon savings to efficiency measures based on the emissions rate of the marginal technology offset will most likely result in an unintended emissions outcome and either over- or underincentivize efficiency relative to an optimal policy. Appendix B provides the detailed steps to derive equation 16.

\subsection{Interstate/lnterregional Issues}

Given the interconnected nature of the U.S. electricity grid and the large amount of electricity that is transferred across state lines, the reduction in generation associated with an increase in end-use efficiency does not always take place in the state in which the efficiency improvement was implemented. To put it another way, efficiency improvements implemented in one state (or region) may result in a decrease in generation and associated carbon emissions in another state (or region). Although there are emissions benefits associated with the efficiency improvements, those benefits do not necessarily accrue to the implementing state, but rather accrue to the state(s) where generation and emissions are reduced. This can pose a number of challenges when efficiency measures are used for compliance in neighboring states that do not share the same policy.

In order to highlight the challenges associated with interstate efficiency effects, we discuss a suite of two-state examples (four scenarios in total) that explores the implications of interstate efficiency effects under a range of alternative policy combinations and provide potential solutions that address these challenges. ${ }^{30}$ In each scenario, it is assumed that an efficiency program, such as a residential lighting program, in one state, the "implementing state," drives

\footnotetext{
${ }^{30}$ These scenarios can also be interpreted as two-region scenarios in which each region would represent a group of collaborating states that all adopted the same policy.
} 
emissions reductions in another state, the "neighboring state." 31 The scenarios differ by the policies that are assumed to have been adopted by each state.

In addition to the scenario-specific solutions we identify for addressing the challenges, it is worth emphasizing at the outset that the interstate challenges that arise under these mixed policy scenarios can be mitigated, or in some cases eliminated, by expanding the geographic boundary over which a single policy applies. If multiple states agree to implement a unified approach and are therefore jointly responsible for compliance, the multi-state region recoups the full benefit of the efficiency measure as long as the emissions reductions associated with an efficiency measure occur within one of the participating states - it does not matter if the reductions in electricity consumption and emissions are located within the same state.

Below, we examine the challenges that arise under the following combinations of policies in the implementing and neighboring states and identify potential options for addressing these challenges:

1. Mass-based and mass-based

2. Mass-based and rate-based with efficiency crediting

3. Rate-based with efficiency crediting and mass-based

4. Rate-based with efficiency crediting and rate-based with efficiency crediting.

\section{Scenario 1: Mass-Based and Mass-Based}

First, consider a case in which an efficiency measure implemented in a state with a mass-based policy has no impact on generation or emissions within the implementing state, but reduces generation and emissions in a neighboring state that also has a mass-based policy. Under a massbased policy, compliance is determined by comparing the total quantity of emissions from covered sources within the state to the emissions budget. Assuming the state is in compliance, total emissions will be equal to (or below) the emissions budget. Therefore, irrespective of the location of the emissions reductions associated with the efficiency measure, the emissions outcome is known a priori. Thus, in this example, there is no potential to erode the intended emissions reductions associated with the policies because both states have mass-based policies. However, efficiency measures that solely result in emissions reductions outside the implementing state (or outside of the multi-state region if a multi-state approach is implemented) do not help achieve compliance within the implementing state. The emissions benefits associated with these efficiency measures are effectively "lost" to the neighboring state. As a result, the incentive for the implementing state to pursue efficiency measures that lead to emissions reductions outside of the state is reduced because the value of the emissions reductions accrue to the neighboring state. ${ }^{32}$ The remaining value to the implementing state is solely the value of

\footnotetext{
${ }^{31}$ Reductions in a neighboring state may be more likely if the implementing state is a net-importer of electricity or if the region within the state that is implementing the program is close to a state boarder.

${ }^{32}$ In practice, it is more likely that an efficiency improvement in the implementing state would lead to emission reductions in both the implementing and neighboring state rather than solely in the neighboring state. In this case, the incentive for the implementing state to invest in an efficiency improvement for purposes of compliance with the mass-policy would scale with the degree to which the emissions reductions associated with the improvement occur within the state.
} 
avoided electricity consumption - the reduced amount of electricity purchased. However, given that these efficiency measures may be low-cost options for reducing emissions in the neighboring state, it may be advantageous for the neighboring state to share the cost of these efficiency measures with the implementing state so that the full incentive to invest in these lowcost measures is maintained: the implementing state has an incentive to invest in order to recoup the cost savings associated with avoided electricity consumption and the neighboring state has an incentive to invest in order to recoup the emissions benefits.

\section{Scenario 2: Mass-Based and Rate-Based With Efficiency Crediting}

In the second scenario, an efficiency measure implemented in a state with a mass-based policy reduces generation and emissions in a state with a rate-based policy with efficiency crediting. Similar to the first scenario, the intended emissions reduction of the two policies are not eroded in this case because the budget is preserved in the implementing state and emissions can only decrease in the neighboring state (because the rate target is fixed and the achieved generation will decrease). Again, similar to Scenario 1, the incentive for the implementing state (with the mass-based policy) to invest in efficiency measures is reduced because the implementing state does not recoup the benefit of the reduction in emissions resulting from the efficiency measure. Thus the value of an efficiency measure to the implementing state scales with the degree to which those measures reduce emissions in-state.

In this example, although the emissions reductions are not eroded in the neighboring state (the state with a rate-based policy), there is an ambiguous effect of the reduced emissions on the neighboring state's adjusted intensity fraction and, as a result, on its burden of compliance. Recall that under a rate-based policy with efficiency crediting, compliance is assessed by ensuring that the state's adjusted intensity is lower than the target:

$$
\frac{\text { Emissions }}{\text { Generation }+ \text { Electricity Savings }} \leq \text { Target }
$$

In this example, both emissions and generation in the neighboring state decrease as a result of the efficiency improvements in the implementing state. These reductions can lead to either an increase or a decrease in the adjusted intensity, depending on whether the carbon intensity of the generation reduced is greater than or less than the target intensity. This poses a challenge for the neighboring state because the efficiency actions in other states could either help or hurt efforts to achieve compliance. One approach that could be used to correct this is for states with rate-based standards to treat in-state reductions in generation that resulted from out-of-state efficiency measures as in-state electricity savings, either explicitly or through a trading program. This approach effectively gives credit to the neighboring state for reductions in generation, even though those reductions were the result of efficiency measures in the implementing state. In this example, emissions and generation would still both decrease in the neighboring state, but the effective electricity savings (the reductions in generation in the neighboring state) would increase in an amount equal to the decrease in generation. Therefore, the adjusted intensity would decrease relative to a situation in which in-state reductions are not credited (because the numerator, emissions, would remain constant and the denominator would increase), helping the neighboring state to achieve compliance. This would also create an incentive for the neighboring state to pursue efficiency measures within the implementing state or, alternatively, to share costs 
of efficiency measures with the implementing state that lead to emissions benefits in the neighboring state.

\section{Scenario 3: Rate-Based with Efficiency Crediting and Mass-Based}

Under scenario 3, in which a state with a rate-based policy implements an efficiency measure that results in an emissions reduction in a state with a mass-based policy, a new complication stems from the accounting of the electricity savings in the calculation of the implementing state's adjusted intensity. Specifically, if the electricity savings are credited within the calculation of the adjusted intensity in the implementing state, the adjusted intensity will decrease even though emissions have remained unchanged. As a result, emissions reductions are effectively double counted: once in the implementing state via crediting of the electricity savings (even though they resulted in no in-state emissions reductions) and once in the mass-based policy state where the reductions in emissions associated with the efficiency measure contribute to compliance with the emissions budget. This leads to erosion of the total emissions reduction relative to what would be achieved in the absence of crediting of electricity savings in the implementing state. Moreover, this creates a perverse incentive for the implementing state to pursue efficiency measures that do not result in in-state emission reductions. This perverse incentive could be corrected by crediting only electricity savings in the implementing state that result in emissions reductions within the implementing state. Finally, similar to scenario 1, the neighboring state (with the mass-based policy) has an incentive to invest in efficiency measures in the implementing state that yield emissions reductions in the neighboring state.

\section{Scenario 4: Rate-Based With Efficiency Crediting and Rate-Based With Efficiency Crediting}

Lastly, under scenario 4, in which both the implementing and neighboring states have a ratebased policy with efficiency crediting, issues arise with regard to the calculation of the adjusted intensity in both states. In the implementing state, crediting of electricity savings that leads solely to emissions reductions in the neighboring state would result in an increase in the implementing state's emissions relative to what would have been achieved without crediting of savings. The adjusted intensity would decrease even though emissions have not changed. Therefore, the implementing state could increase emissions while still maintaining compliance. Assuming emitting more would allow use of cheaper forms of generation, crediting the savings in this way would lead to an increase in emissions. This issue could be addressed using the same correction proposed in scenario 3, namely having the implementing state only credit electricity savings that result in emissions reductions within the implementing state. In the neighboring state, emissions would be reduced as a result of the efficiency measure, but the effect of the efficiency measure on the burden of compliance is ambiguous; similar to scenario 2, it could be increased or decreased. Therefore, savings that result in emissions reductions within the neighboring state could be credited in the calculation of the adjusted intensity in the neighboring state. As in the other scenarios, the neighboring state has an incentive to invest in efficiency measures in the implementing state that reduce generation in the neighboring state.

Table 4 below summarizes the challenges that arise under the 4 scenarios described above. 
Table 4. Summary of the Interstate Issues That Arise When Efficiency Measures in One State Lead to Generation and Emissions Effects in Neighboring States

\begin{tabular}{|c|c|c|c|}
\hline & \multicolumn{2}{|c|}{$\begin{array}{l}\text { Compliance Approach of State in Which Efficiency is Implemented } \\
\text { (referred to as the Implementing State) }\end{array}$} \\
\hline & & Mass-Based & Rate-Based with Efficiency Crediting \\
\hline \multirow{2}{*}{ 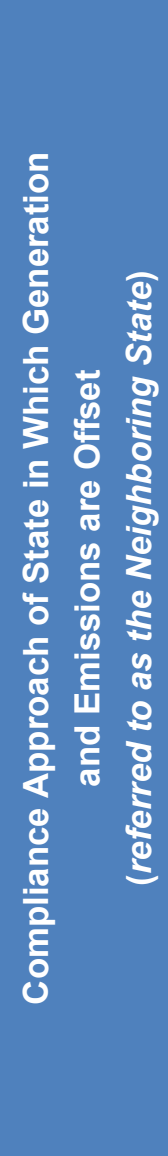 } & $\begin{array}{l}\text { D } \\
\$ \\
0 \\
\mathbb{0} \\
0 \\
0 \\
0 \\
0 \\
0 \\
\end{array}$ & $\begin{array}{l}\text { Scenario } 1 \\
\text { Emissions outcome is certain. } \\
\text { Incentive to procure energy efficiency } \\
\text { may be reduced because the } \\
\text { implementing state does not receive the } \\
\text { emissions benefit. }\end{array}$ & $\begin{array}{l}\text { Scenario } 3 \\
\text { Emissions outcome will be eroded if credit } \\
\text { is explicitly or implicitly assigned in the } \\
\text { implementing state in addition to the } \\
\text { neighboring state. } \\
\text { Perverse incentives exist for the } \\
\text { implementing state to implement efficiency } \\
\text { measures that do not result in in-state } \\
\text { emission reductions. } \\
\text { Potential to double count emissions } \\
\text { reductions and erode the intended emissions } \\
\text { outcome. }\end{array}$ \\
\hline & 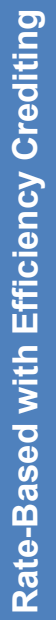 & $\begin{array}{l}\text { Scenario } 2 \\
\text { Emissions outcome is bounded-total } \\
\text { emissions are either equal to or less } \\
\text { than the intended outcome. } \\
\text { Incentive to procure energy efficiency } \\
\text { may be reduced because the } \\
\text { implementing state does not receive the } \\
\text { emissions benefit. } \\
\text { Cost of compliance in the neighboring } \\
\text { state (rate-based policy state) could } \\
\text { increase or decrease depending on the } \\
\text { carbon intensity of generation offset by } \\
\text { the savings. }\end{array}$ & $\begin{array}{l}\text { Scenario } 4 \\
\text { Emissions outcome may be eroded if credit } \\
\text { is explicitly or implicitly assigned in the } \\
\text { implementing state in addition to the } \\
\text { neighboring state. } \\
\text { Perverse incentives exist for the } \\
\text { implementing state to implement efficiency } \\
\text { measures that do not result in in-state } \\
\text { emission reductions. } \\
\text { Cost of compliance in the neighboring state } \\
\text { (rate-based policy state) may be affected } \\
\text { depending on the carbon intensity of } \\
\text { generation offset by the savings. }\end{array}$ \\
\hline
\end{tabular}

In order to resolve the issues that arise under the scenarios described above, it would be necessary to develop a mechanism to track the amount of electricity savings resulting from efficiency and the location of the generation offset by the savings. With this level of detailed information on electricity savings and their effects on generation, it would be possible for states to correctly distribute the efficiency benefits between affected states and therefore to equitably share costs of efficiency measures based on the benefits recouped.

One simple approach to tracking the generation impacts of the electricity savings is to discount electricity savings based on the import fraction aggregated over the compliance period. ${ }^{33}$ Alternatively, as described briefly above, expanding the geographic boundary over which a

\footnotetext{
${ }^{33}$ The import fraction is the ratio of net electricity imports to total electricity consumption:import fraction $=$ $\frac{\text { imports-exports }}{\text { total consumption. }}$. Specifically, states would need to apply a factor of $(1-$ import fraction $)$ to electricity savings if the state were a net importer of electricity.
} 
single policy applies would reduce the potential for interstate efficiency effects and any issues they cause. Under this type of approach, as the area sharing a compliance plan increases, the risk of "losing" emissions reductions associated with efficiency programs implemented within the region, double-counting of emissions savings resulting from efficiency improvements, or creating any perverse incentives would decrease.

One potential challenge in implementing a multistate policy that relies heavily on efficiency for compliance is that inconsistent evaluation, measurement, and verification (EM\&V) protocols between states could lead to over or undercrediting of electricity savings in some states relative to others. If significant, the differences could create perverse incentives to favor efficiency program implementation in some states over others, and/or lead to inaccurate estimates of the emissions savings associated with electricity savings. Developing robust and standard EM\&V protocols that are accepted and adopted by all participating states would greatly reduce the risk of over or undercrediting savings in some states relative to others. A number of efforts, including the Uniform Methods Project (Jayaweera and Haeri 2013), the Northeast Energy Efficiency Partnerships EM\&V Forum (KEMA and NEEP 2010), and the Northwest Regional Technical Forum (Northwest RTF 2014) ${ }^{34}$ have developed standard protocols to determine the savings from a broad range of efficiency measures and programs. These protocols provide a strong basis on which to develop EM\&V protocols for multistate regions.

${ }^{34}$ See http://rtf.nwcouncil.org/measures/Default.asp, accessed June 2016 


\section{Conclusions}

The selection of a policy to reduce GHG emissions from the power sector has significant implications for end-use efficiency. The policy will affect the incentives created for investment in efficiency measures, the need to estimate the electricity savings associated with the measures, and the need to track the regional impacts of the electricity savings on the power system. Massbased policies, with the exception of those that freely allocate allowances to generators or LSEs based on output, have been widely shown to provide economically efficient incentives for both supply- and demand-side options for reducing carbon in the power sector. On the other hand, traditional rate-based policies, as a result of the output subsidy they create, provide a reduced incentive for energy efficiency measures relative to supply-side options for reducing emissions.

In this report, we demonstrate that the distortion between supply- and demand-side options can be eliminated by allowing electricity savings from energy efficiency measures to contribute towards compliance with the rate-based policy. This is achieved by either crediting electricity savings as a source of generation in the denominator of the carbon intensity fraction or equivalently, by assigning avoided emissions credit to electricity savings in the numerator of the intensity fraction at the rate of the target (in other words, by subtracting the product of the electricity savings and the target intensity from the numerator). Alternative approaches to assigning electricity savings with avoided emissions credit, such as crediting at the intensity of generation on the margin when the savings occur, result in either too many or too few avoided emissions credits to electricity savings. Assigning avoided emissions credit at the target rate or treating electricity savings as a source of generation extends the output subsidy to efficiency measures, and thereby eliminates the distortion between supply- and demand-side abatement measures and recovers the same relative incentives for supply- and demand-side measures as achieved under a mass-based policy. Although this modification to the traditional rate-based policy eliminates the distortion between these measures, it does not mitigate the distortionary effect that the output subsidy has on electricity prices, and therefore does not recover the same absolute incentives for efficiency measures.

Although a rate-based policy, if designed effectively, can recover equivalent relative incentives to a mass-based policy, the implementation of a rate-based policy with efficiency crediting creates some additional challenges that are avoided under a mass-based program. Rate-based policies with efficiency crediting require estimates of the achieved electricity savings in order to assess compliance with the standard. Inaccurate estimates of the savings can lead to erosion of the intended emissions goals of the policy. Thus, under a rate-based policy with efficiency crediting, robust estimates of the electricity savings are crucial for ensuring achievement of emissions goals. Furthermore, if neighboring states implement rate-based policies with different targets or a mix of rate- and mass-based policies, tracking the regionality of the generation impacts of efficiency measures will be required to avoid double-counting of efficiency benefits or creating perverse incentives. 


\section{References}

Aldy, Joseph E. 2012. Promoting clean energy in the American power sector: A proposal for a national clean energy standard. Environ. Law Rep. 42:10131-10149

Allcott, Hunt, and Michael Greenstone. 2012. “Is There an Energy Efficiency Gap?” Journal of Economic Perspectives 26(1):3-28.

Allcott, Hunt, and Sendhil Mullainathan. 2010. "Behavior and Energy Policy." Science 327(5970):1204-1205.

Arimura, Toshi H., Shanjun Li, Richard G. Newell, and Karen Palmer. 2012. “CostEffectiveness of Electricity Energy Efficiency Programs.” Energy Journal 33(2):63-99.

Baumol, William J., and Wallace E. Oates. 1988. The Theory of Environmental Policy. Cambridge: Cambridge University Press.

Burtraw, Dallas, Danny Kahn, and Karen Palmer. 2005. $\mathrm{CO}_{2}$ Allowance Allocation in the Regional Greenhouse Gas Initiative and the Effect on Electricity Investors. RFF DP 05-55. Washington, D.C.: Resources for the Future.

Choi Granade, Hannah, Jon Creys, Anton Derkach, Philip Farese, Scott Nyquist, and Ken Ostrowski. 2009. Unlocking Energy Efficiency in the U.S. Economy. New York: McKinsey \& Company.

EPRI (Electric Power Research Institute). 2014. Assessment of Achievable Potential From Energy Efficiency and Demand Response Programs in the U.S. (2010-2030). Palo Alto, CA: Electric Power Research Institute.

Fell, Harrison., Daniel Kaffine, and Daniel C. Steinberg. Forthcoming. Energy Efficiency and Intensity Standards.

Fischer, Carolyn, and Richard G. Newell. 2008. "Environmental and Technology Policies for Climate Mitigation.” Journal of Environmental Economics and Management 55:142-162.

Fischer, Carolyn. 2001. Rebating Environmental Policy Revenues: Output-Based Allocations and Tradable Performance Standards. Discussion Paper 01-22. Washington, D.C.: Resources for the Future.

Gilleo, Annie, Anne Chittum, Kate Farley, Max Neubauer, Seth Nowak, David Ribeiro, and Shruti Vaidyanathan. 2014. The 2014 State Energy Efficiency Scorecard. Research Report U1408. Washington, D.C.: American Council for an Energy-Efficient Economy (ACEEE).

Gillingham, Kenneth, and Karen Palmer. 2014. "Bridging the Energy Efficiency Gap: Policy Insights From Economic Theory and Empirical Evidence." Review of Environmental Economics and Policy 8(1):18-38. 
Gillingham, Kenneth, Richard G. Newell, and Karen Palmer. 2009. "Energy Efficiency Economics and Policy." Annual Review of Resource Economics 1:597-620.

Hahn, Robert and Robert Stavins. 2010. "The Effect of Allowance Allocations on Cap-andTrade System Performance.” Journal of Law and Economics 54(4):S267-S294.

Heeter, Jenny, and Lori Bird. 2013. "Including Alternative Resources in State Renewable Portfolio Standards: Current Design and Implementation Experience." Energy Policy 61:13881399.

Helfand, Gloria E. 1991. "Standards versus standards: the effects of different pollution restrictions." American Economic Review 81(3):622-634.

Interagency Working Group on the Social Cost of Carbon, U.S. Government. 2013. Technical Support Document - Technical Update on the Social Cost of Carbon for Regulatory Impact Analysis - Under Executive Order 12866.

https://www.whitehouse.gov/sites/default/files/omb/inforeg/social_cost_of_carbon_for_ria 2013 update.pdf, accessed June 2015.

Jayaweera, Tina, and Hossein Haeri. 2013. The Uniform Methods Project for Determining Energy Efficiency Savings for Specific Measures. NREL/SR-7A30-53827. Work performed by the Cadmus Group, Portland, Oregon. Golden, CO: National Renewable Energy Laboratory.

KEMA and NEEP (Northeast Energy Efficiency Partnerships). 2010. Common EM\&V Methods and Savings Assumptions Project. Lexington, MA: Northeast Energy Efficiency Partnerships.

Kopp, Raymond J., and William A. Pizer. 2007. Assessing U.S. Climate Policy Options: A Report Summarizing Work at RFF as part of the Inter-Industry U.S. Climate Policy Forum. Washington, D.C.: Resources for the Future.

Meier, Alan, Jan Wright, and A. Rosenfeld. 1983. Supplying Energy Through Greater Efficiency. Berkeley, CA: University of California Press.

NAS (National Academy of Sciences). 2010. Real Prospects for Energy Efficiency in the United States. Washington, D.C: National Academies Press.

Northwest Regional Technical Forum. 2014. Roadmap for the Assessment of Energy Efficiency Measures.

http://rtf.nwcouncil.org/subcommittees/Guidelines/RTF\%20Guidelines\%20(revised\%206-172014).pdf.

Paul, Anthony, Karen Palmer, and Matt Woerman. 2014. Designing by Degrees: Flexibility and Cost-Effectiveness in Climate Policy. RFF DP 14-05. Washington, D.C.: Resources for the Future.

Pigou, Alfred C. 1920. The Economics of Welfare. London: Macmillan. 
Schwartz, Lisa, G. Leventis, S. Schiller, E. Martin Fadrhonc, J. Shenot, K. Colburn, and C. James. Forthcoming. Energy Efficiency as a Least-Cost Strategy to Reduce Greenhouse Gas Emissions and Meet Energy Needs in the Power Sector. Washington, D.C.: State and Local Energy Efficiency Action Network.

Sijm, Jos, Yishu Chen, and Benjamin F. Hobbs. 2012. "The impact of power market structure on $\mathrm{CO}_{2}$ cost pass-through to electricity prices under quantity competition - a theoretical approach." Energy Economics 34(4):1143-1152.

Steinberg, Daniel C., and Owen Zinaman. 2014. State Energy Efficiency Resource Standards: Design, Status, and Impacts. NREL/TP-6A20-61023. Golden, CO: National Renewable Energy Laboratory.

Stobaugh, Robert, and Daniel Yergin, eds. 1979. Energy Future: Report of the Energy Project at the Harvard Business School. New York: Random House. 


\section{Appendix A. Options to Cost-Effectively Achieve Energy Efficiency Goals ${ }^{35}$ \\ Energy Efficiency Pathways}

The main body of this report discusses the economic incentives for investment in energy efficiency improvements that are created under mass- and rate-based policies. Furthermore, it examines how those policies can be designed to create economically efficient incentives for enduse efficiency improvements. Creating economically efficient incentives for energy efficiency improvements is crucial for encouraging investment in efficiency improvements. However, in order to address the broader range of market and behavioral failures that can influence decisionmaking around efficiency measure implementation, additional policies may be necessary to implement. This appendix, reviews the options - or pathways - that state and local government agencies can choose to cost-effectively increase consumers' uptake of energy efficiency and help reduce emissions. These pathways can be pursued regardless of the policy measures chosen to reduce GHGs from the power sector. A pathway is a set of interdependent activities that results in specific energy savings streams and avoided air emissions over a period of time (as well as achieving other objectives such as job growth). These activities can take the form of policies, regulations, programs, or projects - familiar tools to state and local officials:

- Policies are objectives, criteria, or courses of action established by governors, mayors, legislatures, city councils, agencies of state or local governments, and businesses. These policies may promote or provide incentives, either directly or indirectly, for efficiencyinduced savings.

- Regulations are established by local or state agencies to implement policies by prescribing or proscribing conduct by those subject to the regulation. Regulations may require specific levels of efficiency savings or promote or provide incentives for efficiency-induced savings.

- Programs are activities, strategies, or approaches undertaken by a state, utility, contractor, private company, or other entity that directly result in efficiency-induced energy savings.

- Projects are activities involving one or more energy efficiency measures installed at a single facility or site.

Policies and regulations alone do not necessarily result in energy savings. Programs, and the efficiency projects they support, are the vehicles by which policies and regulations are implemented, and energy savings are delivered. Savings typically are quantified at the program or project level.

Activities that make up a pathway are overseen by one or more responsible entities, occur in a specific timing sequence, and can be supported for success through common infrastructure elements such as marketing strategies and workforce development.

35 Excerpted from Schwartz et al., forthcoming. 
Pathways can be combined into a state portfolio designed to obtain a specified level of energy savings or emissions reductions that build over time to meet overall policy objectives. Thus, pathways can be thought of as discrete wedges, each delivering a portion of an overarching energy savings or emissions reduction goal, which can be stacked to achieve the goal in its entirety. In other words, a state's portfolio of multiple energy efficiency pathways is designed to reach the goal.

States can choose among a myriad of potential portfolios by combining pathways in different ways. Variations in portfolios also can come from adjusting the level of energy savings or emissions reductions each pathway contributes to the overall target over time.

Example pathways include the following:

1. Ratepayer-funded efficiency programs, such as those delivered by investor- and publiclyowned utilities and third-party energy efficiency administrators

2. Building energy codes, including code adoption and compliance

3. Local government-led efforts, including benchmarking and disclosing building energy use and making local government-owned assets energy-efficient

4. State lead-by-example activities, including energy savings performance contracting

5. Efforts by large commercial and industrial energy users, including energy management and combined heat and power systems.

These pathways are exemplary of the types of energy efficiency strategies states and local governments use. They do not represent an exhaustive list of options that might be considered. Each jurisdiction tailors its solutions based on its own characteristics and objectives.

Portfolios are dynamic over time. They can be modified in response to their success rate and to adapt to new opportunities and challenges. Changing and adding pathways also can occur as states gain more experience and the underlying energy efficiency infrastructure matures (e.g., more energy efficiency contractors are available and consumers are more aware of energy saving opportunities).

\section{Energy Efficiency Delivery Infrastructure}

Beyond establishing policies, regulations, programs and projects through one or more energy efficiency pathways, several forms of infrastructure support must be in place to deliver efficiency benefits on an ongoing basis. For example, consumers need to demand energy efficiency services and products, and qualified contractors and retailers need to be available to provide them. The following four areas support a range of energy efficiency pathways:

1. Administrative infrastructure. An administrative infrastructure for effective implementation of energy efficiency policies is critical for success. This can include designation, by legislation or executive order, of a lead agency for oversight, as well as providing the resources it needs to implement the policies. For example, the state can designate a lead agency to improve the energy efficiency of existing and new government-owned and leased facilities, including establishing contracting protocols for efficiency projects installed by energy services companies. 
2. Marketing, education and outreach. A long-term goal for energy efficiency is market transformation, defined as widespread, permanent changes in the way that energy efficiency markets operate - for example, how manufacturers, distributors, retailers, consumers, and others sell and buy energy-related products and services. A key element of market transformation is establishing consumer awareness and demand for energy efficiency products and services. Governments can partner with the private sector to support marketing, education, and outreach programs through such activities as promoting the federal Energy Star brand, public service announcements on ways to use electricity efficiently, and social media campaigns with energy-saving tips and links to efficiency programs and contractor networks.

3. Workforce training and development. Developing and delivering successful energy efficiency programs and achieving targeted energy savings requires a qualified workforce. For energy-efficient technologies to realize their full potential, there must be adequately trained people to design, manage, install, operate, and maintain them. Energy efficiency workforce services can be categorized into five types:
A. Planning and project management
B. Consulting and energy advisory services
C. Construction and installation
D. Evaluation, monitoring, and verification
E. Operations and maintenance.

There are a number of paths to building a qualified workforce to provide energy efficiency services. For example, states can grant licenses to contractors trained in proper installation, and operation and maintenance of energy-efficient equipment, and state colleges and universities can provide workforce training and education. Industry can partner with states and educational institutions and recognize practitioners trained in energy efficiency services through certifications. In addition, government and industry can develop national skill standards.

4. Market services and product development. These programs help local businesses develop capabilities to deliver energy efficiency service and product offerings in a profitable manner, over a long period of time, in support of a state's energy efficiency goals. Examples of government-supported market services and product development programs include:
A. Outreach efforts to make businesses aware of opportunities
B. Incentives to manufacturers and distributors to make their products more efficient and more widely available, and incentives to local contractors to expand services
C. Loan and incentive programs for businesses that relocate, offer energy efficiency services and products, and hire new staff to meet the demand for efficiency. 


\section{Appendix B. Emissions Crediting of Electricity Savings From Energy Efficiency Under a Rate-Based Policy}

\section{Derivation of the Equivalency Between the Denominator Adjusted Intensity Fraction and the Numerator Adjusted Intensity Fraction: Why Estimates of the Marginal Emissions Rates Are Not Required for Compliance Assessment}

In the main body of this report, we show that crediting electricity savings in the denominator of the intensity fraction is equivalent to crediting the electricity savings in the numerator at the rate of the achieved adjusted emissions intensity. Below we provide the detailed steps to derive that equivalency.

First, recall that under a rate-based policy with efficiency crediting, the adjusted intensity, $I_{A}$, or the ratio of the emissions net of credits to the sum of generation and electricity savings must be less than or equal to the target intensity, $I_{T}$ :

$$
I_{A}=\frac{E_{i}-C_{i}}{G_{i}+G_{E E}} \leq I_{T}
$$

Where $E_{i}$ is the emissions from generator $i, C_{i}$ is the amount of credits owed (or purchased, assuming compliance) by generator $i, G_{i}$ is the amount of electricity generated by generator $i$, and $G_{E E}$ is the amount of electricity savings purchased or achieved by generator $i$. Also note that in the case that compliance with the standard is achieved, $I_{A}$, the adjusted intensity, is equal to the target intensity, $I_{T}$.

Rearranging equation B-1, as shown below, demonstrates that the numerator approach, which effectively assigns emissions credits to electricity savings at the rate of the target intensity, is equivalent to the denominator approach, which effectively treats electricity savings as a loadserving technology:

$$
\begin{aligned}
& I_{A}\left(G_{i}+G_{E E}\right)=E_{i}-C_{i} \\
& I_{A} G_{i}+I_{A} G_{E E}=E_{i}-C_{i} \\
& I_{A} G_{i}=E_{i}-C_{i}-I_{A} G_{E E} \\
& I_{A}=\frac{E_{i}-C_{i}-I_{A} G_{E E}}{G_{i}} \\
& I_{A}=\frac{E_{i}-C_{i}-I_{A} G_{E E}}{G_{i}}=\frac{E_{i}-C_{i}}{G_{i}+G_{E E}} \leq I_{T}
\end{aligned}
$$

Thus, the under a rate-based standard with efficiency crediting, the emissions avoided by the efficiency measures is solely dependent on the achieved intensity, $I_{A}$. It is not necessary to estimate what marginal generation technology was offset by the savings in order to assign 
emissions credit to the efficiency savings. The next section demonstrates that assigning credit based on the offset technology can, in fact, erode the intended emissions outcome of the policy.

\section{Evaluation of Alternative Crediting Approaches}

In the main body of this report we show that a traditional rate-based policy that does not account for the emissions effects of electricity savings leads to a reduced incentive for investment in energy efficiency measures relative to the incentives created under a mass-based policy with a full auction. However, we demonstrate that equivalent relative incentives can be recouped if the rate-based policy is modified to account for the emissions effects of the electricity savings. Specifically, we show that equivalent relative incentives are recovered by either adding electricity savings to the denominator of the net intensity fraction as shown in equation B-1, which we refer to as the "denominator adjustment", or, by subtracting the product of electricity savings and the achieved adjusted intensity ${ }^{36}$ from the numerator as shown in B-5, which we will refer to as the "numerator adjustment." The product of electricity savings and the achieved intensity yields a value in tons of emissions, and because this value is subtracted from the achieved emissions, $E_{i}$, in the numerator approach, this approach effectively gives avoided emissions credit to electricity savings at the rate of achieved intensity.

A number of other approaches to assigning credit to electricity savings have been proposed in the context of a rate-based standard, including crediting emissions at the rate of the carbon intensity of the generation unit offset by the electricity savings and crediting at the average carbon intensity of the power pool. However, as we demonstrate in the examples below, these approaches assign either too few or too many avoided emissions credits to electricity savings and as a result, can lead to erosion of the intended emissions outcomes of the policy. In order to demonstrate this, we calculate the emissions outcomes in a series of examples in which a ratebased policy is applied to a hypothetical generation system. Under each example we vary what type of generation is offset by the energy efficiency measure and calculate the equilibrium emissions outcomes that would be achieved under selected approaches for crediting electricity savings. Thus for each example, we examine the emissions outcomes when the following three crediting approaches are used:

1) Denominator adjustment:

$$
\frac{E_{i}-C_{i}}{G_{i}+G_{E E}} \leq I_{T}
$$

2) Numerator adjustment with Crediting at the Achieved Adjusted Intensity: 37

$$
\frac{E_{i}-C_{i}-I_{A} G_{E E}}{G_{i}} \leq I_{T}
$$

3) Numerator adjustment with Crediting at the intensity of off set generation:

$$
\frac{E_{i}-C_{i}-I_{\text {Offset }} G_{E E}}{G_{i}} \leq I_{T}
$$

\footnotetext{
${ }^{36}$ Note that the achieved adjusted intensity is evaluated over the duration of a compliance period. In other words, the emissions, electricity savings, credits, and generation values that are used in calculating the adjusted intensity are their sums over the compliance period.

${ }^{37}$ Note that as shown above, the denominator adjustment and numerator adjustment that credits electricity savings at the rate of the achieved adjusted intensity are mathematically equivalent. However, we include both here to demonstrate equivalence under an application.
} 
Under all cases we assume inelastic demand for energy services, or in other words, that the sum of generation and energy savings remains constant. We show that the intended emissions outcomes of the policy are only recovered under the denominator adjustment and the numerator adjustment that credits electricity savings at the achieved adjusted intensity, while crediting at the rate of offset generation can lead to either lower or higher emissions than intended, depending on the generation offset. Although it is not explored in a detailed example, we also discuss the implications of crediting at the carbon intensity of the power pool.

In the discussion below, we will refer to the numerator approach that credits electricity savings at the achieved adjusted intensity as the "numerator-achieved" approach and the numerator approach that credits electricity savings at the intensity of offset generation as the "numeratoroffset" approach.

First, assume there is a generation system with coal, NGCC, and wind generation capacity. Assume that the carbon intensities of coal generation and NGCC generation are $2000 \mathrm{lbs} / \mathrm{MWh}$ and $1000 \mathrm{lbs} / \mathrm{MWh}$, respectively and that demand for electricity is $1000 \mathrm{MWh} /$ year and is inelastic. Furthermore, assume that the generation mix of the system in year 1 of operation is as shown in Table B-1, and that generation from wind is fixed and non-dispatchable. Because wind capacity is fixed and non-dispatchable, the generation cannot be shifted from one part of the year to another and cannot increase.

Table B-1. The Generation Mix of the Model Generation System Under No-Policy (Year 1)

\begin{tabular}{rrc} 
Load-Serving Resource & & Initial System \\
\cline { 1 - 1 } Coal Gen [MWh] & & 500 \\
NGCC Gen [MWh] & & 400 \\
Wind Gen [MWh] & & 100 \\
EE "Gen" [MWh] & & 0 \\
\hline Emissions [lbs]: & & $1,400,000$ \\
\hline
\end{tabular}

Given the carbon intensities specified above, the generation mix in year 1 results in emissions of 1.4 million $\mathrm{lbs}$ of $\mathrm{CO}_{2}$ and an emissions intensity of $1,400 \mathrm{lbs} / \mathrm{MWh}$.

Now assume that in year 2 a rate-based policy with efficiency crediting is implemented with a target intensity of 1,200 lbs/MWh. Furthermore, assume that in year two the ordering of the marginal cost of generation sources during the majority of hours is cost wind $<$ cost coal $<$ cost NGCC. In order for the system to comply with the policy, the carbon intensity must decrease. Given the limited technologies available, there are only two options to reduce the emissions intensity: replace coal generation with generation from NGCC, or use efficiency to offset generation from either coal or natural gas. Recall that wind capacity is non-dispatchable, so in this system, there is no opportunity to achieve emissions reductions by increasing generation from wind and decreasing generation from coal or NGCC units.

\section{Example 1: System Achieves Compliance with Supply-Side Options}

Let us first consider a case in which the system equilibrates under the new policy without employing energy efficiency. For the sake of this example, assume that efficiency measures do 
not exist or that they are very expensive. Table B-2 shows how the system adjusts from the initial mix in order to achieve compliance with the target.

Table B-2. The Equilibrium Generation Mix Under No-Policy and Under the Rate-Based Policy With Efficiency Crediting

\begin{tabular}{|c|c|c|}
\hline & $\begin{array}{c}\text { Year } 1 \\
\text { No Policy }\end{array}$ & $\begin{array}{c}\text { Year } 2 \\
\text { Policy = Rate-EE }\end{array}$ \\
\hline & Initial System & $\begin{array}{c}\text { Equilibrium } \\
\text { (No Efficiency) }\end{array}$ \\
\hline Coal Gen [MWh] & 500 & 300 \\
\hline NGCC Gen [MWh] & 400 & 600 \\
\hline Wind Gen [MWh] & 100 & 100 \\
\hline EE "Gen" [MWh] & 0 & 0 \\
\hline Emissions [lbs]: & $1,400,000$ & $1,200,000$ \\
\hline $\begin{array}{r}\text { Adj. Intensity - Denominator Adjustment } \\
(\text { eq. } A 7) \\
{[\mathrm{lbs} / \mathrm{MWh}]:}\end{array}$ & 1,400 & 1,200 \\
\hline $\begin{array}{r}\text { Adj. Intensity - Numerator Adjustment } \\
\text { Credit Savings at Achieved Intensity (eq. A8) } \\
\text { [lbs/MWh]: }\end{array}$ & 1,400 & 1,200 \\
\hline $\begin{array}{r}\text { Adj. Intensity - Numerator Adjustment } \\
\text { Credit Savings at Intensity of Offset Gen (eq. A9) } \\
\text { [lbs/MWh]: }\end{array}$ & 1,400 & 1,200 \\
\hline
\end{tabular}

Assuming compliance is achieved through supply-side only measures (coal to gas fuel switching) Note: Recall that the assumed $\mathrm{CO}_{2}$ emissions intensity of coal generation is $2000 \mathrm{lbs} / \mathrm{MWh}$ and the assumed $\mathrm{CO}_{2}$ emissions intensity of NGCC generation is $1000 \mathrm{lbs} / \mathrm{MWh}$; target rate for policy is 1200 $\mathrm{lbs} / \mathrm{MWh}$.

The system as dispatched in year 1 is not in compliance because the adjusted intensity is greater than the target. Given the assumed constraints on the system, the cheapest way to reduce the system's intensity to achieve compliance in year 2 would be to decrease generation from coal from $500 \mathrm{MWh}$ to $300 \mathrm{MWh}$ and to increase generation from NGCC from $400 \mathrm{MWh}$ to 600 MWh. Given that no efficiency measures have been implemented, this achieves an adjusted intensity of 1,200 lbs/MWh under all approaches for crediting electricity savings and results in a reduction of emissions of $200,000 \mathrm{lbs}$. Given that the policy results in $200,000 \mathrm{lbs}$ of $\mathrm{CO}_{2}$ emissions reductions when compliance is achieved solely through supply-side measures, we consider this reduction in emissions the intended emissions outcome of the policy, and the level of emissions that should be recovered under approaches that credit electricity savings.

\section{Example 2: Efficiency Measures Offset 150 MWh of Coal Generation}

In a second example, let us assume that an energy efficiency measure is implemented during year 2 that reduces consumption of electricity by $150 \mathrm{MWh}$. Thus, total consumption of electricity over year 2 is reduced from 1,000 MWh to $850 \mathrm{MWh}$. Furthermore, let us assume that the electricity savings occur at a time when coal is the marginal technology, and as a result the 
efficiency measure offsets $150 \mathrm{MWh}$ of coal generation. Table B-3 shows the static (or nonequilibrium) impact of the efficiency measure.

Table B-3. The Static or Non-Equilibrium Effect of Electricity Savings on the Generation Mix Assuming The Electricity Savings Offset Coal Generation

\begin{tabular}{|c|c|c|}
\hline & $\begin{array}{c}\text { Year } 1 \\
\text { No Policy }\end{array}$ & $\begin{array}{c}\text { Year } 2 \\
\text { Policy = Rate-EE }\end{array}$ \\
\hline & Initial System & $\begin{array}{c}\text { Non- } \\
\text { Equilibrium } \\
\text { (Static Change) }\end{array}$ \\
\hline Coal Gen [MWh] & 500 & 350 \\
\hline NGCC Gen [MWh] & 400 & 400 \\
\hline Wind Gen [MWh] & 100 & 100 \\
\hline EE "Gen" [MWh] & 0 & 150 \\
\hline Emissions [lbs]: & $1,400,000$ & $1,100,000$ \\
\hline $\begin{array}{r}\text { Adjusted Intensity } \\
\text { Denominator Approach } \\
(\text { eq. A7) } \\
{[\text { lbs/MWh]: }}\end{array}$ & 1,400 & 1,100 \\
\hline $\begin{array}{r}\text { Adjusted Intensity } \\
\text { Numerator-Achieved Approach } \\
\text { (eq. A8) } \\
{[\mathrm{lbs} / \mathrm{MWh}]:}\end{array}$ & 1,400 & 1,100 \\
\hline $\begin{array}{r}\text { Adjusted Intensity } \\
\text { Numerator-Offset Approach } \\
\text { (eq. A9) } \\
{[\text { lbs/MWh]: }}\end{array}$ & 1,400 & 941 \\
\hline
\end{tabular}

Note: The assumed target rate for policy is $1200 \mathrm{lbs} / \mathrm{MWh}$.

The electricity savings offset coal generation and therefore reduce total emissions to 1.1 million lbs. This reduction in emissions causes the adjusted intensity to decrease to a level below the target intensity (1,200 lbs/MWh) under all three approaches for crediting savings. Therefore, emissions can increase relative to this non-equilibrium state while maintaining compliance with the target. In other words, emissions can be higher during other times of the compliance period. Table B-4 shows the equilibrium conditions under all the crediting approaches. 
Table B-4. Equilibrium Generation Mix Under No-Policy and Under The Rate-Based Policy With Efficiency Crediting When an Efficiency Measure Offsets Coal Generation

\begin{tabular}{|c|c|c|c|c|c|}
\hline & & & (Case A) & (Case B) & (Case C) \\
\hline & $\begin{array}{c}\text { Year } 1 \\
\text { No Policy }\end{array}$ & $\begin{array}{c}\text { Year } 2 \\
\text { Policy = Rate-EE }\end{array}$ & $\begin{array}{c}\text { Year } 2 \\
\text { Policy }=\text { Rate-EE }\end{array}$ & $\begin{array}{c}\text { Year } 2 \\
\text { Policy = Rate- } \\
\text { EE } \\
\end{array}$ & $\begin{array}{c}\text { Year } 2 \\
\text { Policy = Rate- } \\
\text { EE } \\
\end{array}$ \\
\hline & Initial System & $\begin{array}{c}\text { Non- } \\
\text { Equilibrium } \\
\text { (Static Change) }\end{array}$ & $\begin{array}{l}\text { Equilibrium } \\
\text { Denominator } \\
\text { Adjustment }\end{array}$ & $\begin{array}{l}\text { Equilibrium } \\
\text { Numerator- } \\
\text { Achieved }\end{array}$ & $\begin{array}{l}\text { Equilibrium } \\
\text { Numerator- } \\
\text { Offset }\end{array}$ \\
\hline Coal Gen [MWh] & 500 & 350 & 450 & 450 & 570 \\
\hline NGCC Gen [MWh] & 400 & 400 & 300 & 300 & 180 \\
\hline Wind Gen [MWh] & 100 & 100 & 100 & 100 & 100 \\
\hline EE "Gen" [MWh] & 0 & 150 & 150 & 150 & 150 \\
\hline Emissions [lbs]: & $1,400,000$ & $1,100,000$ & $1,200,000$ & $1,200,000$ & $1,320,000$ \\
\hline $\begin{array}{r}\text { Adjusted Intensity } \\
\text { Denominator Approach } \\
\text { (eq. A7) } \\
{[\text { lbs/MWh]: }}\end{array}$ & 1,400 & 1,100 & 1,200 & 1,200 & 1,320 \\
\hline $\begin{array}{r}\text { Adjusted Intensity } \\
\text { Numerator-Achieved Approach } \\
\text { (eq. A8) } \\
{[\text { lbs/MWh]: }}\end{array}$ & 1,400 & 1,100 & 1,200 & 1,200 & 1,320 \\
\hline $\begin{array}{r}\text { Adjusted Intensity } \\
\text { Numerator-Offset Approach } \\
\text { (eq. A9) } \\
\text { [lbs/MWh]: }\end{array}$ & 1,400 & 941 & 1,059 & 1,059 & 1,200 \\
\hline
\end{tabular}

Note: The assumed target rate for policy is $1200 \mathrm{lbs} / \mathrm{MWh}$. 
Under the denominator approach as shown in case A of Table B-4 (and the equivalent numerator-achieved approach in case B), coal generation increases from the non-equilibrium state by $100 \mathrm{MWh}$ and NGCC generation decreases by $100 \mathrm{MWh}$. This results in cost savings relative to the non-equilibrium state (because coal generation is cheaper than gas generation), but maintains compliance with the policy - note that the adjusted intensity is equal to the target at 1,200 lbs/MWh. Relative to the no policy (year 1) generation mix, the equilibrium generation mix results in 200,000 lbs of emissions savings. This is the same emissions outcome as that in example 1 in which compliance was achieved solely through redispatch from coal to NGCC generation. Thus, the denominator approach and the equivalent numerator-achieved approach recoup the same emissions outcomes as the case in which only supply-side abatement options were used.

Notice that the non-equilibrium adjusted intensity differs depending on how electricity savings are credited. The adjusted intensity as calculated using the numerator-offset approach, which credits savings at the rate of offset generation, in this case coal, is lower than the adjusted intensity as calculated using the numerator-achieved approach (or equivalently, the denominator approach). Therefore, the numerator-offset approach allows for a greater increase in emissions between the non-equilibrium and equilibrium state relative to the numerator-achieved or denominator approach. Thus, when least-cost equilibrium is achieved in this example, total emissions under the numerator-offset approach are greater than total emissions under the denominator approach or the equivalent numerator-achieved approach. Specifically, under the numerator-offset approach in case C of Table B-4, coal generation increases by $220 \mathrm{MWh}$ relative to the non-equilibrium state and NGCC generation decreases by $220 \mathrm{MWh}$ because there is more "room" for emissions. This results in $120,000 \mathrm{lbs}$ of additional emissions relative to the numerator-achieved approach and correspondingly, 120,000 lbs more than if compliance is achieved solely with supply-side abatement options. Thus, the intended emissions outcome of the policy is eroded when electricity savings are credited at the rate of offset generation.

This effect is due to the fact that, in this case, electricity savings are effectively being overcredited. Electricity savings are assigned credit at the carbon intensity of coal generation. Assigning credit at this rate implicitly assumes that the emissions during the time of the year when the electricity savings are not realized (i.e., when the efficiency measures are not operating) remain constant. However, as discussed earlier, the reduction in emissions at the time the electricity savings are realized allows emissions to increase at other times of the year because the electricity savings have effectively caused over-compliance with the policy. Thus, the total impact of electricity savings on emissions is lower than the product of electricity savings and the carbon intensity of coal generation.

In short, the effect of the electricity savings on emissions over the whole compliance period must be considered, not solely the effect at the time when the savings are realized. Thus, in the case when electricity savings offset coal generation (or more generally, if the savings offset a technology with a carbon intensity greater than the target), assigning electricity savings avoided emissions credit at the carbon intensity of offset generation results in over-crediting of electricity savings and an increase in emissions relative to the intended outcome. The next example will show that when electricity savings offset a technology with a lower carbon intensity than the target, crediting savings at the intensity of offset generation results in under-crediting of electricity savings and lower emissions relative to the intended outcome. 


\section{Example 3: Efficiency Measures Offset 150 MWh of NGCC Generation}

In a third example, similar to example 2, let us assume that an energy efficiency measure is implemented during year 2 that reduces consumption of electricity by $150 \mathrm{MWh}$, but in this case let us assume that NGCC generation rather than coal generation is offset by the savings. Thus, total consumption of electricity over year 2 is reduced from 1,000 MWh to $850 \mathrm{MWh}$, and 150 MWh of NGCC generation is offset. Table B-5 shows the static (or non-equilibrium) impact of the efficiency measure, and the equilibrium generation mix under the alternative approaches for crediting electricity savings. 
Table B-5. Equilibrium Generation Mix Under No-Policy and Under the Rate-Based Policy With Efficiency Crediting When an Efficiency Measure Offsets NGCC Generation

\begin{tabular}{|c|c|c|c|c|c|}
\hline & & & (Case A) & (Case B) & (Case C) \\
\hline & $\begin{array}{c}\text { Year } 1 \\
\text { No Policy } \\
\end{array}$ & $\begin{array}{c}\text { Year } 2 \\
\text { Policy }=\text { Rate-EE }\end{array}$ & $\begin{array}{c}\text { Year } 2 \\
\text { Policy }=\text { Rate-EE }\end{array}$ & $\begin{array}{c}\text { Year } 2 \\
\text { Policy = Rate- } \\
\text { EE } \\
\end{array}$ & $\begin{array}{c}\text { Year } 2 \\
\text { Policy = Rate- } \\
\text { EE } \\
\end{array}$ \\
\hline & Initial System & $\begin{array}{c}\text { Non- } \\
\text { Equilibrium } \\
\text { (Static Change) }\end{array}$ & $\begin{array}{l}\text { Equilibrium } \\
\text { Denominator } \\
\text { Adjustment }\end{array}$ & $\begin{array}{l}\text { Equilibrium } \\
\text { Numerator- } \\
\text { Achieved }\end{array}$ & $\begin{array}{l}\text { Equilibrium } \\
\text { Numerator- } \\
\text { Offset }\end{array}$ \\
\hline Coal Gen [MWh] & 500 & 500 & 450 & 450 & 420 \\
\hline NGCC Gen [MWh] & 400 & 250 & 300 & 300 & 330 \\
\hline Wind Gen [MWh] & 100 & 100 & 100 & 100 & 100 \\
\hline EE "Gen" [MWh] & 0 & 150 & 150 & 150 & 150 \\
\hline Emissions [lbs]: & $1,400,000$ & $1,250,000$ & $1,200,000$ & $1,200,000$ & $1,170,000$ \\
\hline $\begin{array}{r}\text { Adjusted Intensity } \\
\text { Denominator Approach } \\
\text { (eq. A7) } \\
{[\text { lbs/MWh]: }}\end{array}$ & 1,400 & 1,250 & 1,200 & 1,200 & 1,170 \\
\hline $\begin{array}{r}\text { Adjusted Intensity } \\
\text { Numerator-Achieved Approach } \\
(\text { eq. A8) } \\
{[\text { lbs/MWh]: }}\end{array}$ & 1,400 & 1,250 & 1,200 & 1,200 & 1,170 \\
\hline $\begin{array}{r}\text { Adjusted Intensity } \\
\text { Numerator-Offset Approach } \\
\text { (eq. A9) } \\
\text { [lbs/MWh]: }\end{array}$ & 1,400 & 1,294 & 1,235 & 1,235 & 1,200 \\
\hline
\end{tabular}

Note: The assumed target rate for policy is $1200 \mathrm{lbs} / \mathrm{MWh}$ 
In contrast to example 2, in this case, the electricity savings in isolation do not bring the system into compliance with the policy. Under the denominator and numerator-achieved approach, the non-equilibrium adjusted intensity falls to $1,250 \mathrm{lbs} / \mathrm{MWh}$ while the adjusted intensity under the numerator-offset approach falls to $1,294 \mathrm{lbs} / \mathrm{MWh}$. As a result, under all three crediting approaches, emissions must be reduced even further from the non-equilibrium state in order to bring the system into compliance with the intensity target. However, because the adjusted intensity under the numerator-offset approach is greater than the fraction under the denominator or equivalent numerator-achieved approach, the required emissions reductions to achieve compliance will also have to be greater.

In contrast to example 2, in this case, assigning avoided emissions credit to electricity savings based on the intensity of the generation technology offset gives too little credit to electricity savings. Although the direction of this effect is the opposite of that under numerator-offset crediting in example 2, the cause is the same: the effect of the efficiency measure is not determined solely by the emissions impact at the time that the electricity savings are realized but by the total effect of savings over the entire year. Therefore, the electricity savings should be assigned credit at a rate that reflects the total emissions effects over the entire year, not at a rate that reflects solely the instantaneous offset generation. Namely, the electricity savings should be credited using either the denominator or the equivalent numerator-achieved approach.

\section{Crediting at the Carbon Intensity of the Power Pool}

A final approach that has been proposed is to assign credit for avoided emissions to electricity savings at the average carbon intensity of the power-pool. This approach will only yield the same crediting rate as the denominator or numerator-achieved approaches if the boundaries of the power-pool correspond to the boundaries of the state (or group of states) over which the same target applies. Given that power-pools do not typically follow state boundaries, this is unlikely to be the case. As a result, similar to crediting at the carbon intensity of offset generation, crediting at the carbon intensity of the power pool will lead to either over- or under-crediting of electricity savings because the intensity of the power pool will not necessarily correspond to the achieved adjusted intensity within the compliance region.

\section{Summary}

Assigning credit to electricity savings based on the carbon intensity of offset generation implicitly ignores the total effects of the electricity savings over the entire year (or compliance period) and therefore results in over- or under-crediting of electricity savings with avoided emissions. If the electricity savings offset a generator with an intensity greater than the target, then the savings are over-credited. If the savings offset a generator with an intensity less than the target, then the savings are under-credited. Assigning credit to electricity savings based on the average carbon intensity of the power pool implicitly assumes that the boundaries of the ratebased policy correspond to the boundaries of the state. Given that power pools do not typically follow state lines, this will similarly lead to over- or under-crediting of electricity savings with avoided emissions. Crediting electricity savings at the rate of the achieved adjusted intensity (the numerator-achieved approach) or equivalently counting electricity savings in the denominator of the intensity (the denominator approach) results in a crediting rate that reflects the integrated effect of the efficiency measure on emissions over the entire compliance period. 